\title{
MIGRACIONES, MANO DE OBRA Y FORMACIÓN DE UN PROLETARIADO RURAL EN TUCUMÁN, ARGENTINA, 1870-1914
}

\author{
JORGE BALÁN \\ Instituto Torcuato Di Tella
}

LA APERTURA al mercado internacional, hacia la segunda mitad del siglo XIX, generó en gran parte de América Latina una demanda creciente de mano de obra, en especial en sectores económicos nuevos, ubicados a menudo en regiones de asentamiento demográfico reciente y escaso y organizados productivamente en forma diferente de otros sectores económicos. Aunque más evidente en la actividad exportadora agropecuaria y minera, esta demanda se amplió a otras ramas de la economía, como la construcción de obras públicas, la producción agrícola e industrial para el mercado interno, comercio y transporte y los servicios en general. La novedad en cuanto a actividad productiva, ubicación geográfica y forma de organización de parte importante de la economía exportadora y sectores íntimamente ligados a ella, dada la escasez crónica de mano de obra, provocó cambios profundos y rápidos en la inserción productiva de la fuerza de trabajo. ${ }^{1}$ Como regla, tales cambios resultan más fáciles cuando son simultáneos con un cambio en su composición demográfica, sea vía migraciones $o$, de manera más lenta, por la entrada de nuevas generaciones de trabajadores, que cuando se dan cambios en la población previamente inserta en formas arcaicas de producción y organización social en la misma región. ${ }^{2}$

Tal renovación no fue total ni unidireccional. Por el contrario, estructuras arcaicas fueron incorporadas en diverso grado y las formas organizativas nuevas incluyeron tanto modeĺos capitalistas "puros" como otros basados en el trabajo servil. De hecho, se encuentra considerable heterogeneidad en los mismos sectores exportadores que tomaron la punta en el proceso de crecimiento dentro del marco neocolonial, atribuible a factores diversos tales como la tecnología productiva típica de un cierto

1 Roberto Cortés Conde discute cinco casos de desarrollo de la economía exportadora con especial énfasis en los cambios en el mercado de trabajo en su libro Hispanoamérica: la apertura al comercio mundial, 1850-1930, Buenos Aires, Paidós, 1974.

2 Jorge Balán, "Introducción", en Migración y desarrollo: Consideraciones teóricas y aspectos socieconómicos y políticos, Buenos Aires, Clacso, 1973. 
bien en ese momento histórico, así como al tipo de la clase dominante que orientó el proceso y el origen de la mano de obra ocupada. La heterogeneidad caracterizó también a los sectores que crecieron impulsados por la expansión de las exportaciones.

Como hemos insistido en otro lugar, ${ }^{3}$ el papel clave que jugó la migración, interna y externa, en la solución al problema de la mano de obra durante el período, y la importancia crucial de este problema en la conformación de la economía y sociedad neocoloniales en América Latina, invita a estudiar aquéllos para entender mejor a éstas. Es bien sabido que condiciones especiales en varios países europeos favorecieron una fuerte emigración trasatlántica, en parte dirigida a países de América Latina y en especial al cono sur. También se produjo una inmigración considerable de trabajadores serviles, llamados genéricamente "coolies", originarios de China, Corea y la India, y fue común, en especial en el Caribe, el traslado internacional de "coolies" o trabajadores serviles de otros orígenes étnicos. Aparte de corrientes migratorias internacionales e intercontinentales de magnitud, se produjeron al mismo tiempo migraciones internas de importancia. De hecho, unas y otras respondían a causas comunes, recurriéndose a la mano de obra extranjera cuando la nacional era escasa, socialmente no disponible, inadaptable a corto plazo al sistema nuevo en expansión, de "baja calidad", cara, o reuniese una combinación compleja de estas características. En sentido inverso, dentro del territorio nacional, se movilizó mano de obra para sectores en expansión cuando, además de no existir localmente, la importada involucrase una alta inversión inicial (como el caso de la importación de esclavos - la contratación de "coolies"), salarios más altos (como el caso de la inmigración de origen europeo), inadaptabilidad al sector nuevo (como en el régimen de plantación), etc.

El punto de vista general de este trabajo es que hay una relación íntima entre el origen de la mano de obra incorporada, su forma de reclutamiento e inserción en la producción, y la organización social de los sectores productivos en cuestión. Dicha relación es compleja y no admite generalizaciones simples de causa y efecto. Además, se da dentro de un contexto histórico específico que incluye por lo menos otros dos elementos estructurales básicos que no se discutirán en detalle en este trabajo: el origen del capital y los capitalistas como clase y la tecnología de producción típica del sector en expansión en ese momento histórico. Desde nuestro punto de vista, ambas variables son condicionantes de, y están condicionadas por, la fuerza de trabajo incorporada y la organización productiva.

El objetivo de este trabajo es describir en un caso histórico concreto la economía azucarera en Tucumán de 1870 a 1914, cómo fue solucio-

3 Jorge Balán, "Migraçoes e desenvolvimento capitalista no Brasil: ensaio de interpretaçao histórico-comparativa", Estudos CEBRAP, 5, julio-agosto-septiembre de 1973, pp. 7-79. 
nado el problema de la mano de obra y qué determinó la solución adoptada y con qué consecuencias para la sociedad y economía tucumanas. Las respuestas son provisorias, ya que utilizamos datos de una investigación en curso que todavía tiene importantes huecos empíricos. En la primera parte del artículo se discutirá el contexto dentro del cual se dio la expansión de la economía azucarera en Tucumán hacia el último cuarto del siglo pasado. La segunda parte estará dedicada al problema de la mano de obra, las alternativas abiertas y las soluciones adoptadas. Por último, en forma de hipótesis se sugerirá qué consecuencias tuvo para la formación de la economía y sociedad regionales, y en especial para su estructura de clases, la solución adoptada para reclutar y mantener una fuerza de trabajo adecuada en la producción azucarera.

\section{I}

En Argentina el auge de las exportaciones en la segunda mitad del siglo xIx provocó una ampliación notable del mercado interno. Aunque esto ocurrió en muchos otros casos, lo que caracterizó a Argentina en el contexto latinoamericano fue la intensidad con que creció el consumo y la relativa variedad de los bienes demandados, consecuencias de la inusitada rapidez del crecimiento demográfico provocado por la inmigración europea masiva, la distribución igualitaria del ingreso (en relación con otras economías exportadoras) y los altos niveles medios del mismo. La gran expansión del mercado interno dio lugar a un crecimiento sostenido de las importaciones, con posibilidades bastante amplias de ser sustituidas por la producción nacional. Los artículos de consumo popular, en especial productos alimenticios y textiles, figuran clásicamente como aquellos que se prestan con facilidad a un proceso de sustitución de importaciones, tanto por la importancia de recursos naturales cercanos como por la facilidad de importación tecnológica, o incluso de innovación.

La harina de trigo fue el primer artículo de consumo cuya importación fue sustituida en Argentina. La producción cerealera en la provincia de Buenos Aires, practicada en pequeña escala hacia la Independencia, había sufrido una notoria retracción durante varios decenios; hacia 1870 la harina consumida allí era en gran medida importada de Chile y Estados Unidos o en menor escala de provincias del interior. Pocos años después esa provincia, Santa Fe y Córdoba se transformarían en grandes productores de cereales, de hecho en exportadores de primer nivel mundial. El segundo renglón en tiempo e importancia fue el azúcar, como veremos en seguida, y el tercero el vino. Después de la carne y el trigo, con mucho los principales artículos en la dieta argentina, el azúcar y el vino ocupaban lugares de relieve.

Respecto al vino y el azúcar se dieron dos condiciones de gran relevancia para nuestro problema: eran actividades orientadas de manera principal al mercado interno, concentradas en el litoral urbano y la pam- 
pa húmeda, que se localizaron en provincias del interior muy distantes del mercado. Además, a diferencia de otros productos agro-industriales del interior como el tabaco y el algodón, las ventajas de acercar físicamente el sector fabril al agrícola eran enormes. En el caso de la caña de azúcar, el corto límite de tiempo entre corte de la planta y la molienda y el alto costo del transporte, por necesidad implicaban la proximidad y gran densidad de actividades agroindustriales. A esta descripción somera debe agregarse otro elemento crucial: la tecnología de la producción de azúcar había sido revolucionada hacia mediados del siglo, con lo que aumentó de manera notoria la escala de producción necesaria y con ella la densidad de capital en el sector fabril. ${ }^{4}$

En el mapa 1 se indican los límites reales de Argentina en 1870, la densidad demográfica y los principales caminos. Con él se tiene una idea bastante clara de cuán precario y disperso era el asentamiento poblacional; Argentina, de la que se excluía en el censo de 1869 a la población indígena no integrada, incluía poco más de un tercio del territorio actual donde habitaban menos de dos millones de personas. El principal núcleo de población era ya, después de más de un siglo de crecimiento muy superior al resto del país, la provincia de Buenos Aires, cerca de la ciudad capital. Otros núcleos importantes existían en la vieja ruta del Alto Perú, en especial el noroeste cordobés, Santiago, Tucumán, Salta; en Cuyo todavía volcado más a Chile que a Argentina; y en algunos puntos de las rutas fluvial y terrestre al Paraguay. La economía exportadora, desde el fin de la plata boliviana, se localizó en distintas áreas de la pampa húmeda y el litoral: cueros y carnes secas, lanas y carne de cordero, carnes vacunas enfriadas y cereales, constituyeron en momentos diferentes los productos principales que se derivaron de dicha región. Caña de azúcar, vid, algodón, tabaco, yerba mate, todos se ubicaron a considerable distancia (mil kilómetros o más) de Buenos Aires. En términos relativos, la actividad que demandó un volumen y densidad mayor de mano de obra entre estas actividades de mercado interno y que se localizó entre las regiones del interior en aquella de mayor densidad demográfica, fue la caña de azúcar.

La economía tucumana, afectada durante decenios por la guerra e inseguridad, pérdida de mercados tradicionales y multiplicación de aduanas y otras barreras al comercio interprovincial, retomaba a mediados de siglo el fuerte papel comercial que la había caracterizado hacia fines de la colonia. ${ }^{5}$ La rica producción ganadera permitía una exportación considerable de cueros y ganado en pie. Los abundantes bosques

4 P. P. Courtenay, Plantation Agriculture, Nueva York, Frederich A. Praeger, 1965, pp. 83-95; y Vladimir P. Timoshenko y Boris Swerling, The World's Sugar; Progress and Policy, Stanford, Stanford University Press, 1957.

5 Sobre Tucumán hacia fines del virreinato y durante las guerras de la inde. pendencia, véase Tulio Halperín Donghi, Revolución y guerra: Formación de una élite dirigente en la Argentina criolla, Buenos Aires, Siglo XxI, 1972, pp. 49-52. 
Mapa 1

Argentina, 1870

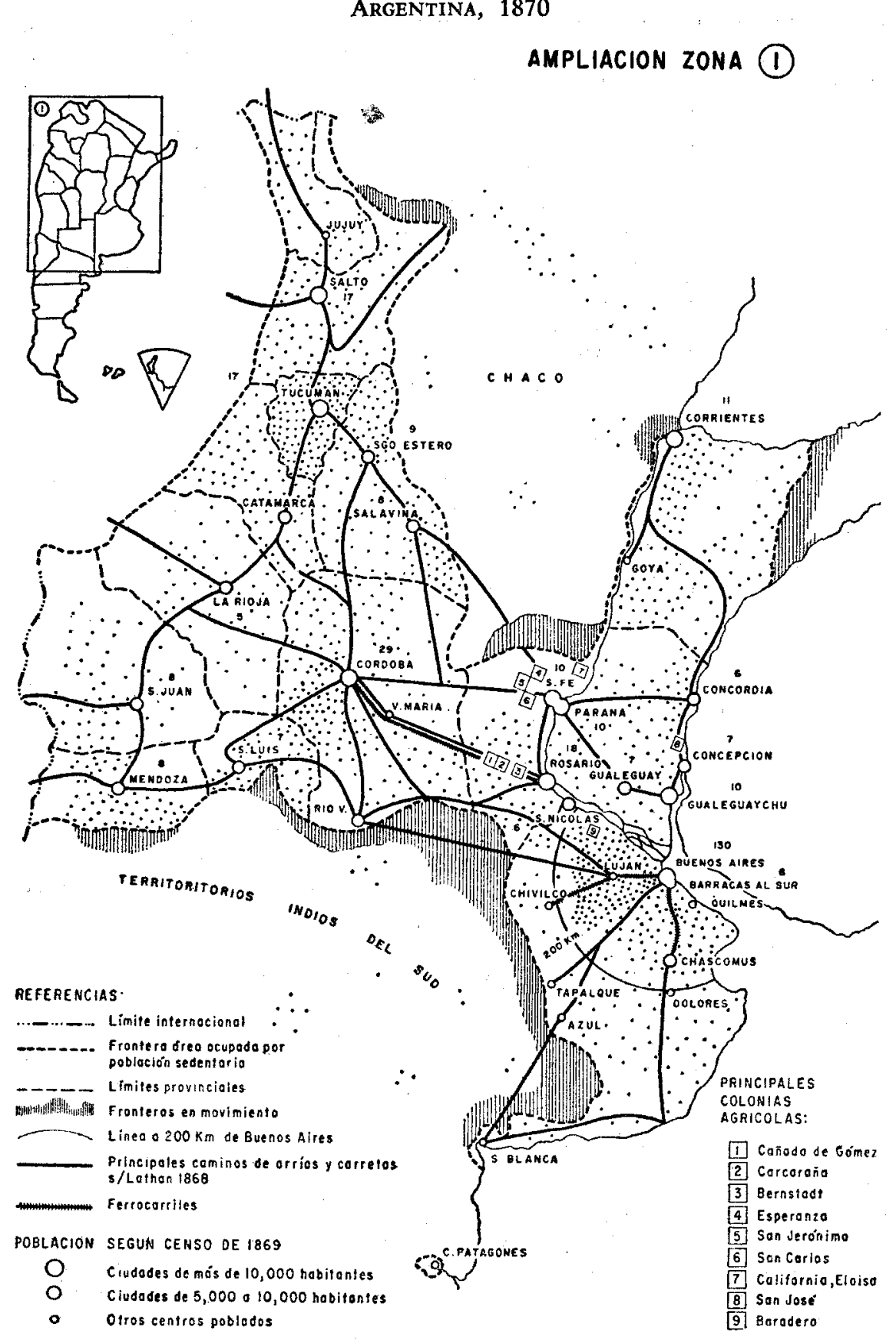

Fuente: Eduardo A. Zalduendo, Las inversiones británicas para la promoción y desarrollo de ferrocarriles en el siglo XIX, tomo II, Buenos Aires, 1969.

Nota: Las cifras sin encuadrar indican miles de pobladores urbanos. Los puntos equivalen a 1000 habitantes. 
daban tanino para la curtidumbre y maderas para, junto con los cueros, fabricar las tradicionales carretas, esenciales para el transporte de entonces. Otros productos locales que encontraban mercados en provincias de la región y a veces en el litoral eran el tabaco, el arroz y la harina de trigo, mientras que el maíz era el principal cultivo para el mercado principal. Pero ya hacia el año 1870 afirmaba un observador que "...la industria de caña-azúcar es hoy la más importante, la que requiere mayor capital y la que ocupa mayor número de operarios". ${ }^{6}$

Aunque sabemos poco sobre la evolución de esta actividad antes del decenio de 1870, no cabe duda que se había expandido durante los dos decenios anteriores, al suplir las necesidades locales y regionales de azúcar y aguardiente. El crecimiento del número de ingenios, todavía primitivo y en su mayoría con trapiches de madera, permite deducir la expansión del cultivo que, en 1874, cuando todavía era en exclusiva un producto con mercado regional, abarcaba por lo menos 2300 hectáreas. ${ }^{7}$ Aunque no tendría entonces la importancia económica de la ganadería, ya se destacaba, como afirmaba el observador antes citado, por la densidad de capital y mano de obra ocupados.

El decenio del 70 fue de grandes cambios que dejaron sentada la posición de Tucumán dentro del sistema nacional; éste giraba ahora alrededor del avasallador predominio económico de Buenos Aires y la pampa húmeda, que asumía la consolidación del Estado nacional y la integración física y económica del territorio. A la paz, relativa sin duda por lo menos hasta 1875 cuando cayeron los últimos grandes caudillos provinciales en el Norte, y la eliminación de las barrerás internas al comercio, se debía adicionar un elemento básico para aumentar el comercio: fletes más baratos que acercasen al mercado ampliado del litoral. En 1869 el gobierno nacional aprobó la extensión del ferrocarril desde Córdoba hasta la frontera norte, pero aseguró la financiación sólo del tramo hasta Tucumán. En 1872 comenzaron las obras y, en plena crisis económica y a pesar de una seria restricción del gasto público desde 1873, se continuó la construcción hasta inaugurar la línea en 1876.

El gobierno provincial, en manos de políticos liberales desde 1869, conjugó hábilmente los intereses agrarios y comerciales de la rica provincia con una política interna de modernización y una presión sobre el gobierno nacional para la defensa de intereses regionales. ${ }^{8}$ Estos, en for-

6 La descripción de Tucumán hacia 1870 está tomada sobre todo de Arsenio Granillo, Provincia de Tucumán: Serie de artículos descriptivos y noticiosos, Tucumán, Imprenta La Razón, 1872. La cita, de la página 107, está tomada de un artículo publicado en "La Juventud" por César Mur.

7 En 1850 había en Tucumán 13 ingenios; en 1860, 24; en 1870, 54; en 1874, 73 y en 1877 llegó a 82 ; pocos años después, en 1881, quedarían sólo 34 "fábricas" de azúcar. Datos tomados de Alfredo Bousquet, et al., Memoria histórica y descriptiva de la Provincia de Tucumán, Buenos Aires, Imprenta M. Biedma, 1882, p. 519.

8 Sobre la política tucumana y la política nacional azucarera véase el impor- 
ma creciente, fueron definidos como los intereses del azúcar. Aunque todavía había esperanzas de reabrir y ampliar vías comerciales con Chile y Bolivia, se hacía cada vez más claro que el futuro mercado era el de Buenos Aires. Los cueros, en el mejor de los casos, suplementarían con beneficios reducidos exportaciones pampeanas; maderas y muebles, en ocasiones pensados como base de una industria regional, afrontarían en cualquier eventualidad fletes costosísimos; el trigo poco podía ofrecer cuando su producción se amplió en la pampa, en tierras más apropiadas y cercanas al mercado. En definitiva, Tucumán ofrecía ventajas en la producción de arroz, azúcar y tabaco para el mercado nacional y clima subtropical húmedo, tierras aptas, población densa.

En el cuadro 1 se presentan datos sobre área cultivada con caña de azúcar para distintos años entre 1874 y 1881, distinguiendo entre explotaciones con capacidad fabril (ingenios) y otras sin ella (cañeros independientes): Debe advertirse que la fuente original utiliza la estadística del pago de patentes provinciales, sistema que gravaba la tierra cultivada según su uso y no la propiedad. Esto es cierto también para estadísticas

\section{Cuadro 1}

TUCUMÁN: SUPERFICIE CUltIVADA, NÚMERO DE PROPIEDADES Y TAMAÑo MEDIO DE INGENIOS Y CAÑEROS INDEPENDIENTES, 1874-1881

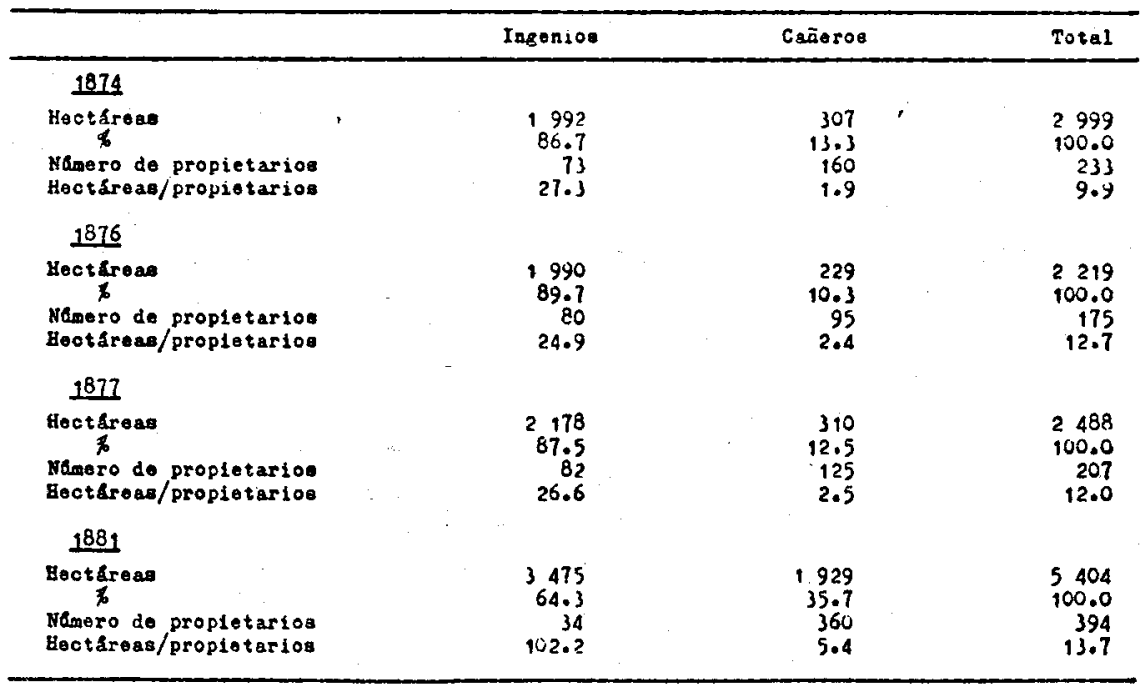

Fuente: Registro estadístico de la provincia de Tucumán. Correspondiente al año 1882. Publicado bajo la dirección del jefe de la Oficina de Estadística General de la misma Provincia, César Mur, Buenos Aires, Imprenta de Pablo E. Coni, 1884 .

tante trabajo de Donna Guy, Politics and the Sugar Industry in Tucuman, Argenfina, 1870-1900, Disertación doctoral, inédita, Universidad de Indiana, 1973. 
posteriores, por lo menos hasta fin de siglo, y en todos los casos debe suponerse que el área cultivada era mayor. Por una parte, muchos propietarios evadían el impuesto declarando un número menor de hectáreas cultivadas. Por la otra, plantadores pequeños, acogiéndose legal o ilegalmente a la disposición que proveía la exención impositiva hasta cierto límite, no figuran en el total. Las estimaciones de la subrepresentación en cuanto a hectáreas cultivadas oscilan entre un máximo de casi $40 \%$, que se obtiene en el año 1895, como diferencia entre el total arrojado por el censo nacional y aquel que surge del pago de patentes provinciales, y $20 \%$ estimado por la mayor autoridad en materia de estadísticas provinciales durante el período. ${ }^{9}$

El crecimiento rápido ocurrido después de la inauguración del ferrocarril en 1876 es aparente. También se observa en el mismo cuadro otro fenómeno concomitante y bien conocido: la fuerte disminución del número de ingenios, cuando algunos de ellos renovaron totalmente su maquinaria y se volvieron mucho más eficientes que los antiguos, desplazándolos. Con ello, se dio un aumento notorio del tamaño medio de las explotaciones de los ingenios, que se quintuplicó en pocos años. También aumentó la superficie media cultivada por los cañeros independientes dado que antiguos ingenios, al cerrar la parte fabril, se convirtieron en simples productores de caña. Así aumentó también la producción de caña cultivada por éstos. Es notoria la existencia de un sector amplio de cultivadores muy pequeños, aunque subestimado por la razón ya indicada, lo que caracterizó a la producción tucumana hasta nuestros días.

El aumento de la producción desde mediados del decenio de 1870 demandó inversiones privadas enormes para la época. Hubo una renovación casi total de maquinaria que, al responder a tecnologías recientes, era muy costosa. Además, los precios de la tierra subieron de manera vertiginosa con la llegada del ferrocarril y si bien los ingenios más importantes tenían extensiones de tierra considerables -o mejor dicho, los mayores terratenientes se volcaron a la producción de caña en forma más intensiva y dieron lugar a los principales ingenios - toda tentativa de concentración demandaba capitales muy fuertes, inexistentes localmente. Debe advertirse que en Tucumán no existían desde hacía tiempo tierras públicas y la división de la propiedad era bastante marcada. ${ }^{10}$ Los mayores terratenientes a los que haciamos referencia serían bastante pequeños en la provincia de Buenos Aires. En consecuencia, los ingenios renovados con gran capacidad de molienda no podían aspirar, como era común hasta 1875, a moler sólo caña propia. Una proporción de tierras

9 Opinión de Rodríguez Marquina, Jefe de la Oficina de Estadística, recogida en Investigación parlamentaria sobre agricultura, ganadería, industrias derivadas y colonización: Anexo G: Tucumán y Santiago del Estero, Buenos Aires, 1898.

10 El problema de la extremada subdivisión de la tierra era ya considerada por Bousquet, y la discusión la retomó Emilio Lahitte en sus anotaciones al informe producido por Antonio M. Correa para la investigación parlamentaria. Véase Investigación parlamentaria, op. cit. 
que oscilaba entre más de un tercio (38\% en 1881, según el cuadro 1) y casi la mitad (si suponemos mayor evasión impositiva entre cañeros independientes, sobre todo pequeños) no pertenecía a ingenios, lo que demuestra que no sólo los grandes ingenios volcaron su tierra a la producción de caña, sino casi cualquier otro propietario dentro de la región favorecida por lluvias abundantes, riego, temperatura adecuada y suelos llanos. Las inversiones en cañaverales nuevos, obras de regadío y caminos eran muy costosas, sobre todo por el ingente uso de mano de obra y por la demora de dos años hasta que se realizaba la primera zafra.

No es de extrañar, dado el volumen del capital requerido y la debilidad del sistema bancario oficial, que se generalizara una situación de endeudamiento que, en último término, descansase en financistas porteños y extranjeros. ${ }^{11}$ Cañeros independientes y colonos de los ingenios trabajaban con adelantos, con los que los ingenios se aseguraban la materia prima a precios estables; éstos, a su vez, recibían créditos para inversiones en maquinaria y adelantos por parte de los grandes comisionistas y distribuidores. Desde la implantación de la primera refinería, que comenzó a trabajar en 1889, ésta también ofrecía adelantos sobre azúcar crudo. Aunque tres grupos financieros porteños con fuertes lazos en Europa actuaron durante el periodo en el negocio azucarero, sin duda el mayor fue el de Ernesto Tornquist \& Cía., que tuvo el papel predominante en la creación de la Refinería Argentina y mantuvo su control accionario y hacia fines de siglo dominaba cinco ingenios importantes que reunían entre el $25 \%$ y $30 \%$ de la producción tucumana de azúcar. Tornquist también jugó un papel clave como comisionista en la obtención de créditos para compra de maquinaria en Europa.$^{22}$ Con todo, los sectores financieros, fuertes por sus habilidades para reunir capitales cuantiosos fuera del alcance de los ingenios tucumanos, por sus conexiones comerciales y por su habilidad política, nunca llegaron a dominar la producción y la cifra antes citada $(30 \%)$ fue el máximo histórico que alcanzaron sólo un año en Tucumán. La base del capital azucarero estuvo en manos tucumanas, aunque muchos fuesen (como en cualquier otra actividad económica del país entonces) inmigrantes extranjeros. ${ }^{13}$

11 Investigación parlamentaria, op. cit., p. 124; y D. Guy, op. cit., p. 331.

12 D. Guy, op. cit., capítulo 5.

$13 \mathrm{La}$ concentración de capitales en la industria azucarera era muy alta, comparable o superior a la que se encontraba en la industria frigorífica y harinera. Por lógica, los capitales extranjeros se vertieron, aparte de la inversión en infraestructura y los préstamos a gobiernos nacionales y provinciales, en los sectores más concentrados (dado que sólo ellos podían proveer de capital necesario o financiarlo en el exterior) a menudo con intermediarios locales. Los tres intermediarios más grandes, Tornquist, Portalis y Bemberg, participaron del negocio azucarero (D. Guy, op. cit.). Pero así como la producción agropecuaria en sí quedó en manos argentinas, la producción cañera y la prolongación fabril de ella quedó en manos tucumanas a pesar de su alta concentración, aunque a costa de considerable articulación entre sectores. La concentración fundiaria fue, por otra parte, casi imposible de conseguir: sólo en algunos momentos se amplió la superficie 
Las inversiones del sector público también fueron importantes sobre todo en los ferrocarriles. El primero unió a Tucumán con Córdoba $\mathrm{y}$, mediante un forzoso cambio debido a la diferencia de trocha, con Rosario; fue completado en 1876 y financiado por el gobierno nacional. Durante años fue el único y sus servicios eran precarios y costosos. Entre 1881 y 1892 se construyeron otras tres líneas y numerosos ramales que servían directamente a la economía azucarera, incluido el que unió Sunchales a Tucumán y permitió la conexión directa con Rosario y Buenos Aires sin cambio de trocha. Prácticamente todos los ingenios quedaron ligados mediante ramales con líneas férreas que les daban acceso a la capital tucumana y al litoral. El costo total, incluido el primer ferrocarril, fue de 62.4 millones de pesos oro. Para tener una idea de la magnitud relativa, debe tenerse en cuenta que el capital declarado de los ingenios tucumanos en 1895 (obviamente subestimado) ascendía a poco más de 44 millones de pesos moneda nacional, 21 de los cuales figuraban como inversión fabril (en 1895 un peso oro valía alrededor de tres pesos moneda nacional).$^{14}$

Una buena parte de la inversión en infraestructura fue, entonces, una forma de subsidio nacional a la economía azucarera tucumana, aunque el desarrollo de ésta permitía ampliamente hacer que dicha inversión fuese rentable. Otro subsidio, más directo y soportado por los consumidores del litoral, fue dado mediante una fuerte protección aduanera, que se elevó en forma acelerada durante el decenio de 1880. Las series de producción, importación, hectáreas cultivadas, precios y tarifas reproducidas en el cuadro 2, así como la gráfica, sirven para ilustrar nítidamente el crecimiento de la economía azucarera y el papel clave de la tarifa aduanera. ${ }^{15}$ En efecto, mientras duró la tarifa más baja, de $25 \%$ sobre el valor hasta 1883, el azúcar tucumano prácticamente no llegó al mercado porteño, solidificándose en el mercado regional, ampliándose a Córdoba y en forma creciente Rosario. Sucesivas alzas, fijando no ya una tarifa ad valorem sino una tasa fija, en pesos oro, fueron elevando la barrera aduanera de tal forma que aún los precios de dumping practicados en

cultivada por los ingenios, pero a largo plazo tendió a disminuir, aun descontando el ocultamiento formal que se produjo después del llamado Laudo Alvear en 1928. Los ingenios de Jujuy y Salta, que comenzaron después y partieron en una etapa que permitió desde el inicio la implantación de tecnología moderna en una región menos subdividida, tuvieron siempre un control casi total sobre la producción cañera. Aun los cañeros independientes han sido siempre más grandes en dichas provincias que en Tucumán.

I4 Datos tomados de la Investigación Parlamentaria. Para el problema de la convertibilidad del peso oro, véase A. G. Ford, El patrón oro: 1880-1914. Inglaterra-Argentina, Buenos Aires, Editorial del Instituto, 1966, cap. V.

15 Debe recordarse que la industria azucarera fue, hasta 1920 , casi en su totalidad tucumana. Sólo entonces comenzó a crecer muy rápidamente la producción del norte (Jujuy y Salta); otras regiones productoras, como el Chaco y Santa Fe, jugaron un papel siempre minoritario. Santiago del Estero tuvo un papel limitado hasta 1890 , y luego nulo. 
ese decenio por diversos países frente a la crisis de sobreproducción no permitían su importación. En 1885 el abandono de la convertibilidad del peso resultó en una creciente devaluación en relación al peso oro, con la consecuente elevación de la tarifa (en 1891 la relación fue de 3 a 1 entre pesos moneda nacional y peso oro, mientras que los precios internos no habían sufrido sino un aumento mucho menor)..$^{18}$ La diferencia tarifaria que gravó más al azúcar refinado desde 1888 fue aplicada en protección de la Refinería Argentina, que comenzó a operar en 1889. Hacia esa fecha, la importación de azúcar sin refinar prácticamente había llegado a cero, pero los gustos de Buenos Aires exigían el azúcar refinada que seguía siendo totalmente importado. En pocos años, hacia 1895, cesó prácticamente toda importación. En ese año se produjo la primera crisis de sobreproducción argentina (en ese momento el $80 \%$ era tucumano) frente a la cual se organizó un trust para exportar dichos excedentes. La exportación fue también subsidiada por el consumidor nacional, mediante un impuesto especial al consumo interno contenido en la ley de primas a la exportación de 1897, que rigió hasta 1904. Las cifras de exportación son elocuentes; pero en 1903 la convención de Bruselas impuso barreras aduaneras al azúcar procedente de paises donde se subsidiaba la exportación, acabando con las posibilidades del azúcar argentino en los mercados externos. ${ }^{17}$

Las series presentadas en el cuadro 2 permiten establecer, dentro del gran período que nos interesa aquí, subperíodos más o menos diferenciados. La primera distinción clara es el año 1895, cuando se satura el mercado interno. Esto permite manejarnos con dos etapas que, además, coinciden convenientemente con fechas censales. Durante la primera, entre el censo nacional de 1869 y el de 1895 , se desarrolló la estructura básica de la producción azucarera tucumana, algunos de cuyos elementos persisten hasta la actualidad. La segunda etapa queda comprendida entre 1895 y 1914, de nuevo para coincidir con el tercer censo nacional, pero también por otras dos razones: la guerra mundial y, poco después en 1916 y 1917, la notoria disminución provocada por heladas sobre la base de cáñaverales viejos y en proceso de degeneración por el llamado "mosaico". Esta crisis, que obligó a importar casi todo el azúcar consumido; a precios muy altos, en 1917, es además importante como fin del período porque de ella se sale con cañaverales nuevos, que introducen criterios genéticos modernos elaborados por la Estación Experimental Agrícola de Tucumán desde su fundación, en 1910: ${ }^{18}$ :

16 El trabajo clásico sobre el abandono del patrón oro es el de J. H. Williams, Argentine International Trade under Inconvertible Paper Money, 1880-1900, Cambridge, Harvard University Press, 1920.

17 Debe recordarse que el alcohol de caña fue siempre un subproducto importante y la política tarifaria, sobre todo la interna, debe incluir a este producto que competía con el alcohol de maíz; este factor sin duda complica el panorama, por lo que no lo discutimos aquí.

18 La evolución técnica de la producción cañera es discutida en forma resu- 
Gráfica 1

AZÚCAR: IMPORTACIÓN, PRODUCCIÓN Y TASAS ADUANERAS, 1870-1915 a

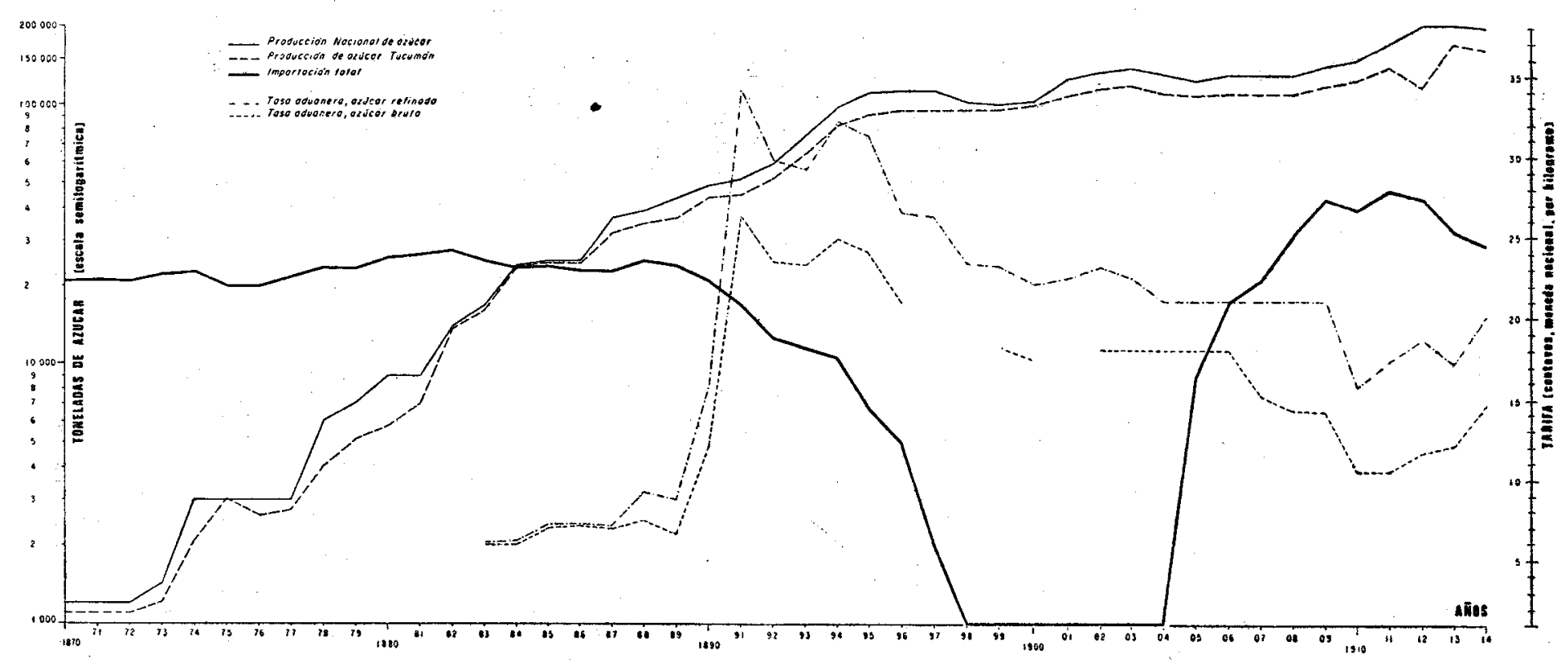

a Los datos de producción e importación son medias móviles quinquenales, estimados con base en las cifras del cuadro 2 . 
El período que más interesa aquí, de manera precisa, por establecerse en él los rasgos básicos de la economía y sociedad regional alrededor del azúcar, es el de 1869-1895. Éste puede dividirse de nuevo en dos hacia el año 1885 , cuando se pone coto a la competencia de azúcares crudos importados en el mercado porteño mediante tarifas notoriamente más altas y en ascenso por abandono de la convertibilidad, y que es cuando el azúcar tucumana comienza a comercializarse masivamente en Buenos Aires. ${ }^{19}$

\section{II}

Desde el principio, el azúcar producido en Tucumán fue caro. Al comienzo del período que discutimos aquí, la producción en pequeña escala con maquinaria primitiva y los altos fletes eran razones más que suficientes para restringir el mercado a límites locales o regionales. Con el ferrocarril y la inversión en maquinaria producida durante el decenio del 80, estas condiciones se alteraron de manera fundamental. Pero el azúcar seguía siendo cara a niveles internacionales y sólo tarifas prohibitivas cerraban el paso al azúcar importado, aunque es cierto que a veces ésta era lanzada a precios de dumping. Las razones aducidas entonces eran muchas, ejemplificadas a menudo con cálculos de costos en los que se traslucían intereses encontrados. Los debates políticos, en especial los motivados por la crisis de superproducción de 1895, son esclarecedores de la diversidad de intereses involucrados y los problemas confrontados por la nueva industria, pero poco se saca en claro sobre por qué el azúcar tucumano era caro. ${ }^{20}$ Los fletes seguían siendo altos; el rendimiento era

mida por Robert E. Evenson y Manuel L. Cordomí, "Sugar Production in Argentina: A Cursory Examination", Cuaderno 69-1 del Instituto de Investigaciones Económicas, Universidad Nacional de Tucumán, mimeografiado.

19 Los primeros temores de superproducción, cuando bajó el precio de la caña de azúcar en 1884 de ocho a seis centavos la arroba, aparecieron cuando la producción tucumana comenzaba a llegar a Buenos Aires y se encontraba con precios inferiores del azúcar importada. Al año siguiente se formó la "Unión Azucarera" para presionar contra la competencia de azúcares importados, sobre todo de Alemania y Francia, que ponía en situación riesgosa a los ingenios cuyos compromisos inmediatos de intereses y amortizaciones eran muy grandes, que sin duda habían sido contraídos esperando la ampliación del mercado al principal centro consumidor del país. Véase en el Boletín del Departamento Nacional de Agricultura los informes de M. Vázquez de la Morena, en vol. 8, 1884, p. 627 y vol. 9, 1885, pp. 197-199.

20 Una comparación detallada con los costos prevalecientes en Cuba demostraban al mismo Vázquez de la Morena, antes citado, que la gran diferencia la hacía el costo de la caña. El ingenio tucumano pagaba (o se pagaba a sí mismo) casi tres veces tanto la tonelada de caña que el ingenio cubano (y aún así dejaba ganancias...). En parte se trataba de rendimientos inferiores, tanto de caña por hectárea como de azúcar por tonelada de caña; pero, el mayor costo de la producción cañera recaía sobre todo en el costo de la mano de obra, aunque esto no es explicitado por el autor (véase el Boletin, vol. 9, 1885, pp. 200-206). El 
bastante bajo, quizás porque el clima tucumano, con numerosas heladas, nunca fue ideal para la caña; ${ }^{21}$ el retraso técnico a nivel agrícola, al menos hasta el segundo decenio de este siglo, era un factor real: la renovación de variedades, que se comenzó a introducir científicamente en Java hacia 1890, recién se comenzó a practicar en Tucumán en 1910 y de hecho tuvo resultados en 1918, cuando las variedades nuevas estuvieron disponibles para reemplazar a los cañaverales diezmados por el mosaico; ${ }^{22}$ las ganancias de los sectores más concentrados eran quizás "excesivas", aprovechando la protección lograda por el peso y la habilidad política de sus defensores, aunque no sin considerable oposición de grupos interesados en la defensa de los consumidores de azúcar: los trabajadores urbanos y la industria alimenticia, uno de cuyos insumos básicos era el azúcar. Todas estas razones eran probablemente ciertas, aunque es difícil de establecer su peso relativo. Pero hay otra razón de importancia crucial, aducida entonces pero nunca evaluada en un contexto más amplio: el precio de la mano de obra.

Para ubicar el problema del costo de la mano de obra en tal contexto, conviene comenzar por una pregunta más radical. ¿Cómo podría pensarse, hacia el último tercio del siglo pasado, en el desarrollo de la producción azucarera en Argentina, país casi despoblado y sin tradición en cultivos tropicales organizados en forma de plantación, cuando el sistema de plantación mismo entraba en crisis en América y la producción azucarera en violenta expansión mundial hacía bajar radicalmente los precios del producto? Es decir, conviene ubicar nuestro problema al considerar tanto la situación del mercado mundial y la crisis de la economía de plantación en el continente, como las desventajas comparativas de Argentina.

Recordemos que había sido en América, y en gran medida con el cultivo de la caña de azúcar, que se había desarrollado la economía de plantación, basada, por una parte, en capitales voluminosos de origen europeo, de gran densidad debido a los costos de apertura de tierras nuevas, instalación de la mano de obra y período relativamente largo de la inversión en cañaverales, y por otra, en una masa densa y disciplinada de trabajadores importados, por lo general esclavos negros, en regiones de baja densidad demográfica. ${ }^{23}$ En el siglo xIX las áreas tradicionales

problema fue retomado más tarde, sobre todo en momentos de crisis (como en 1895 $y$ en 1917) por investigaciones parlamentarias.

21 En realidad las condiciones climáticas en el norte, Salta y Jujuy, son más apropiadas para el cultivo de la caña, pero la estratégica llegada del ferrocarril a Tucumán y su demora en llegar a Salta permitió el desarrollo anterior de dicha provincia. Una vez establecida la preeminencia, resultó imposible eliminarla, aunque la competencia entre las dos regiones dura hasta nuestros días, basada en la mayor concentración agrícola e industrial que existe en Salta y Jujuy. Como se explica más adelante, Santiago del Estero también fue relegado por la política ferroviaria, aunque nunca tuvo posibilidades amplias de desarrollo azucarero.

22 Véase Evenson y Cordomí, op. cit.

23 Courtenay, op. cit., es la principal fuente para la evolución del sistema de 
de plantación entraron en crisis. Las colonias inglesas de las Indias Occidentales, a partir de la abolición de la esclavitud, sufrieron transformaciones importantes, que fueron aceleradas con la apertura del mercado inglés hacia mediados de siglo y la creciente competencia del azúcar de remolacha europea. La importación masiva de trabajadores serviles, en especial los de origen indio, contratados por períodos de cinco años o más, reemplazó a la población negra liberada en los casos en que la existencia de tierras libres favoreció su dispersión. Luego, con la guerra civil en los Estados Unidos, entró en crisis la plantación esclavista que se había desarrollado en ese país desde fines del siglo xvirI como consecuencia de la gran demanda inglesa por algodón. La mayor expansión del sistema de plantación durante este siglo en América se dio en Cuba, donde la persistencia de la esclavitud, la inmigración de plantadores con la revolución haitiana, y la amplitud territorial, permitieron la introducción de escalas mayores en la producción cañera. Pero lo más notable fue la implantación del modelo en Asia y ya en este siglo en África, en parte por la cercanía de la mano de obra densa y disciplinable en tareas agotadoras.

Además, la producción azucarera sufrió un desarrollo técnico notorio, expresado en la creación de las grandes centrales, verdaderos complejos fabriles en medio de los cañaverales extensos que reemplazaron a la multitud de ingenios pequeños e ineficientes. La gran inversión que antes significaba la compra y manutención de esclavos, fue desviada y ampliada con la compra de maquinaria. Sólo en las regiones del mundo en que se dieron las condiciones apropiadas para mantener áreas extensas en el monocultivo cañero (asociado a veces con otro cultivo intensivo para autoconsumo, como el arroz en Java), y la certeza de una oferta estable de mano de obra barata y acceso a mercados grandes, sobrevivió y se amplió el azúcar de caña a pesar de la competencia de la remolacha azucarera.

El* elemento organizativo básico de la plantación, el uso intensivo de mano de obra de baja calificación supervisada estrechamente y disciplinada militarmente, en un sistema de explotación más semejante al fabril o al minero que al agrícola, dentro de organizaciones "totales" - es decir, comunidades relativamente cerradas en las que se realizan todas las actividades sociales-, sobrevivió a la esclavitud pero exigió la formación de un proletariado rural sui generis. ${ }^{24}$ Éste, por regla general, se originó en trabajadores contratados con características serviles (indenture servants en la terminología inglesa) y tendió a conformarse en unidades de homogeneidad étnica dentro de un complejo mayor muy heterogéneo. Si el trabajo servil garantizaba, a los ojos del empresario capitalista, la conti-

plantación, junto con George L. Beckford, Persistent Poverty: Underdevelopment in Plantation Economies of the Third World, Nueva York, Oxford, 1972.

24 El concepto de organización total, utilizado ampliamente por Erving Goffman en sus estudios sociopsicologicos, es propuesto por R. T. Smith para el análisis del sistema de plantación. Véase Beckford, op. cit., p. 9. 
nuidad y precio bajo de la mano de obra necesaria, la bomogeneidad étnica en una situación de casta parece haber sido fundamental para asegurar su disciplina y adaptación a las condiciones de una organización total.

En la Argentina del decenio del 70, tanto los brazos como el capital eran en extremo escasos; con dificultad podría haberse dado una incorporación masiva de ambos en la producción de un artículo como el azúcar, que sólo tenía perspectivas en un mercado interno reducido. El problema de la escasez de brazos, crónico en el litoral pampeano, se planteó desde el comienzo de la expansión azucarera en Tucumán, aun cuando en términos relativos la densidad demográfica era alta en la provincia y en regiones próximas. Según los datos del censo de 1869, Tucumán ya era una provincia receptora de migrantes internos, sobre todo de las provincias vecinas de Catamarca y Santiago del Estero; pero como todas las otras provincias del interior, no había recibido inmigración extranjera de importancia y su población crecía más lentamente que la de provincias del litoral. La esclavitud estaba descartada como posibilidad, nacional e internacionalmente. La importación de coolies fue mencionada en la época, con directa referencia a la expansión de la agricultura de caña de azúcar en el Perú, que había utilizado esta vía. ${ }^{25}$ Pero, además de contradecir de manera frontal los valores europeizantes de la politica de población de la época, demandaba una inversión demasiado cuantiosa para los capitales relativamente pequeños y el futuro modesto de la empresa azucarera en el Tucumán de entonces.

La única solución posible era la mano de obra local y regional o, al menos en forma de especulación habitual en una Argentina en la que el progreso era "ecuacionado" con la inmigración europea, trabajadores de este origen. Estas especulaciones cesaron rápidamente, no porque la población existente en la región solucionase el problema, sino porque resultó demasiado obvia la imposibilidad de atraer colonos europeos para una actividad con fuerte demanda estacional de trabajadores poco califi-

25 Luis J. Aráoz, ministro de gobierno de Tucumán, afirmaba en una carta al jefe del Departamento de Agricultura de la Nación que la inmigración china, fomentada en el Perú, "aquí no conviene" ya que se podía contar con "las indiadas y la inmigración europea". En el mismo contexto señalaba a la falta de brazos como el problema principal en la expansión del cultivo de la caña, esperando que, aunque sea como remedio transitorio, "...en este año dispondrán los plantadores de los indios enviados por el Ministerio de la Guerra". Esto último dicho en referencia a la migración forzosa negociada por Roca de indios pampas capturados en la expedición al desierto, que en dos años o menos fueron diezmados por la enfermedad, la desnutrición y el trabajo en la plantación. La carta de Aráoz está reproducida en el Boletín Mensual del Departamento de Agricultura, II, 1878, pp. 217-218. Sobre la contratación de indios, véase el decreto respectivo y documentos sobre sus consecuencias en La Legislación laboral en Tucumán: Recopilación ordenada de leyes, decretos y resoluciones sobre derecho del trabajo y seguridad social, 1839-1969, Tucumán, Universidad Nacional de Tucumán, 1969, tomo I, pp. 55-60. 
cados, con los peligros supuestos o reales pero sin duda percibidos del trabajo en los trópicos, asimilable en la imagen y la realidad histórica del continente al trabajo esclavo. ${ }^{26}$ Además, obviamente, para atraer inmigrantes europeos hubiera sido necesario equiparar o mejorar los niveles salariales predominantes en la pampa húmeda y las ciudades del litoral, que como veremos más adelante eran superiores a los de Tucumán.

En realidad, la mano de obra local tampoco se adaptaba con facilidad al régimen de trabajo de la plantación azucarera. Proveniente de la ganadería y la agricultura en pequeña escala, en ambos casos con un predominio de producción comercial, se trataba de mano de obra poco abundante y con una tradición de libertad que la hacía poco disciplinable en el sistema rígido y casi burocrático de la plantación. Su reclutamiento y adaptación al trabajo en la economía azucarera fue posible, al final, por una combinación de salarios altos, métodos coercitivos y redes tradicionales sobre la base del estancamiento económico y el crecimiento demográfico de áreas vecinas a la azucarera.

\section{La cuestión salarial}

Hacia el decenio de 1870 puede afirmarse que el trabajo asalariado predominaba como sistema en casi todo el país, aunque como veremos enseguida había claras desviaciones al patrón de trabajo libre, logrados a través de una legislación que reprimía la vagancia y de sistemas coercitivos de reclutamiento para el trabajo rural y el ejército. Aunque no exis. tían sino los rudimentos de un mercado nacional, e inclusive la unidad monetaria no se había logrado, lo que hace aún más riesgosas las comparaciones salariales, parece razonable pensar que las variaciones en el costo de la mano de obra y en los niveles de vida de los trabajadores se expresasen en términos de niveles salariales predominantes y su capacidad adquisitiva. Por ello conviene comenzar el problema con la discusión de algunos datos disponibles sobre salarios en Tucumán, las provincias vecinas de emigración, y Buenos Aires. No existen series regionales de salarios ni parece posible construirlas con datos publicados, aunque datos de archivo nos permitirán más adelante en nuestra investigación tener una idea de la evolución del salario en Tucumán. Los datos con que contamos actualmente se refieren a distintos momentos entre 1870 y 1910 en las

26 En un interesante informe de diciembre de 1882, firmado por "el cuerpo médico de esta ciudad" e intitulado "El estado higiénico de Tucumán” se intenta rebatir la tesis de que el aumento aparente de la mortalidad se deba a las "fiebres intermitentes". Se trata, según los autores, de un efecto del mal estado sanitario y alimenticio de la población pobre, y no del mal tropical. Este argumento, según resulta obvio en el texto, está dirigido a espantar el fantasma del peligro tropical para la inmigración europea. "Hay pocos extranjeros entre los muertos", afirma, con lo que queda demostrado que no es nada ambiental que afectaría a todos. Véase el Boletin del Departamento Nacional de Agricultura, VII, 1883, pp. 40-45. 
Tucumán: Producción e IM

\begin{tabular}{|c|c|c|c|c|c|c|c|c|c|}
\hline \multirow{2}{*}{ Años } & \multicolumn{2}{|c|}{ Produocion } & \multirow{2}{*}{$\begin{array}{l}\text { Produceión } \\
\text { rofinada } \\
\text { (3) }\end{array}$} & \multirow{2}{*}{$\begin{array}{l}\text { Precig } \\
\text { cañag } \\
(4)\end{array}$} & \multicolumn{2}{|c|}{ Importaci $\delta n^{2 /}$} & \multirow{2}{*}{$\begin{array}{c}\text { Exporta } \\
\text { ci6n } \\
\text { (7) }\end{array}$} & \multicolumn{2}{|c|}{ Tarifa aduanerg } \\
\hline & $\begin{array}{l}\text { Tucuman } \\
\text { (1) }\end{array}$ & $\begin{array}{l}\text { Total } \\
\text { (2) }\end{array}$ & & & $\begin{array}{c}\text { Bruta } \\
\text { (5) }\end{array}$ & $\begin{array}{c}\text { Befinada } \\
\text { (6) }\end{array}$ & & $\begin{array}{l}\text { Futa } \\
(8)\end{array}$ & $\begin{array}{c}\text { Refinad } \\
\text { (9) }\end{array}$ \\
\hline 1870 & 1000 & 1000 & - & - & 11415 & $\begin{array}{ll}8 & 184\end{array}$ & - & - & - \\
\hline 187 & 5 & $\overline{-}$ & - & - & 10957 & 7241 & - & - & - \\
\hline & 1200 & 1400 & - & - & 13439 & 11278 & - & - & - \\
\hline 1873 & - & $\because$ & - & - & 12004 & 11866 & - & - & - \\
\hline 87 & - & - & - & - & 10239 & 9694 & - & - & - \\
\hline 1875 & - & - & - & - & 10819 & 12814 & - & $-a 1$ & ad \\
\hline 37. & 3000 & - & - & - & 8699 & 12613 & - & $20 \frac{a}{a}$ & $200 /$ \\
\hline & 3000 & 3000 & - & - & 1648 & 11413 & - & $25 \frac{a}{1} /$ & 25 a d \\
\hline 87 & 2000 & $=$ & $\overline{-}$ & - & $\begin{array}{ll}9 & 176 \\
8 & 030\end{array}$ & 13019 & $=$ & $25 \frac{\omega}{d}$ & 25 d \\
\hline & & & & & & & & 01 & \\
\hline 1880 & 9000 & 9000 & - & 3.0 & 18986 & 11548 & - & $25 \frac{0}{d}$ & $25 \frac{09}{d}$ \\
\hline 88 & 9000 & 9000 & - & 3.4 & 8726 & 17469 & - & $25 \frac{\omega d}{d}$ & $25 \frac{2}{d}$ \\
\hline 年 & & - & 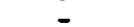 & 6.0 & 3950 & 20069 & $=$ & 5.0 & 5.0 \\
\hline 188 & 24152 & 24152 & - & & 6315 & .28595 & - & & 5.0 \\
\hline 1885 & - & - & - & 3.4 & 1054 & 17983 & - & 6.8 & 6.8 \\
\hline 1886 & & & - & $=$ & & 18. 248 & 1123 & 6.9 & 6.8 \\
\hline $\begin{array}{l}1887 \\
1888\end{array}$ & $24 \underline{500}$ & 24750 & $\bar{z}$ & 7.0 & $\begin{array}{r}18 \\
765\end{array}$ & 22913 & 7 & 6. & $\begin{array}{l}6.9 \\
9.0\end{array}$ \\
\hline & 40843 & 49321 & - & $8-9$ & 1435 & 33031 & 135 & 6 & 8.5 \\
\hline 1890 & & 41000 & 15831 & 12.0 & 3113 & 26428 & 100 & 11.9 & 15.5 \\
\hline 1891 & 41000 & 46366 & 6734 & 14.0 & 1637 & 11200 & 9 & 26.2 & 33.7 \\
\hline $\begin{array}{l}1892 \\
1893\end{array}$ & $\begin{array}{l}53475 \\
50000\end{array}$ & $\begin{array}{l}57696 \\
62000\end{array}$ & $\begin{array}{l}23271 \\
19756\end{array}$ & $\begin{array}{l}20.0 \\
18-20\end{array}$ & $\begin{array}{r}1448 \\
83\end{array}$ & 18324 & 2 & 23.0 & 29.6 \\
\hline & & & & & 3090 & 12062 & & 25.0 & 32.2 \\
\hline
\end{tabular}

1. J. Scheleh, La industria azucarera en su primer centenario, 1821-1921, Bueno 2. La industria azucarera, Buenos Aires, Año LX, Núm. 729, julio de 1954, p. 21 i

3. J. Scheleh, op. cit., p. 126.

4. Departamento Nacional de Agricultura, Argentina, Boletin, 1880, 1883, 1884 tórico", en La industria azucarera, Año LXII, Núm. 752, junio de 1956, pr

5 La industria azucarera, Año LXI, Núm. 745, noviembre de 1955, p. 494.

6. Ibid.

7. F. Latzina, Estadistica retrospectiva del comercio exterior argentino 1875-1904 (para 1886-1904); E. J. Scheleh, op. cit., p. 327 (para 1905-1918).

8. V. Vázquez-Presedo, El caso argentino. Migración de factores, comercio ext estadística de la provincia de Tucumán, correspondiente al año 1896, Bueno 1894); República Argentina, Anuario estadístico, Buenos Aires, 1895, 1896, 1 Nacional del Trabajo, Boletin. Buenos Aires, Núm. 21, noviembre de 1912,

9. La misma fuente de la nota 9 del texto.

a Toneladas. b Centavos por cada 10 kilogramos, moneda nacional.

tres áreas que nos interesa, pero debe tenerse mucho cuidado al interpretar la evolución de los salarios en cada una de ellas a lo largo del tiempo a partir de la información presentada. ${ }^{27}$

27 Las fuentes utilizadas para esta descripción aproximada de los salarios en distintas provincias han sido las siguientes: Tucumán, Arsenio Granillo, Provincia de Tucumán, 1872 (reedición, Tucumán, 1947); Alfredo Bousquet et al., Memoria histórica y descriptiva de la Provincia de Tucumán, Buenos Aires, 1882; Anuario de estadística de la provincia de Tucumán, Buenos Aires, 1895; Juan Bialet Massé, Informe sobre el estado de las clases obreras en el interior de la República. Pre- 
2

ICIÓN DE AZÚCAR, 1870-1918

\begin{tabular}{|c|c|c|c|c|c|c|c|c|}
\hline \multicolumn{2}{|c|}{ Produocion } & & & \multicolumn{2}{|c|}{ Importacion } & \multirow{2}{*}{$\begin{array}{c}\text { Exportg } \\
\text { ciosn } \\
(7)\end{array}$} & \multicolumn{2}{|c|}{ Tarifa acuanera } \\
\hline $\begin{array}{l}\text { Tucumsn } \\
\text { (1) }\end{array}$ & $\begin{array}{l}\text { Total } \\
\text { (2) }\end{array}$ & $\begin{array}{l}\text { refinada } \\
\text { (3) }\end{array}$ & $\begin{array}{l}\operatorname{can} a^{2} \\
(4)\end{array}$ & $\begin{array}{l}\text { Bruta } \\
\text { (5) }\end{array}$ & $\begin{array}{c}\text { Refinada } \\
\text { (6) }\end{array}$ & & $\begin{array}{c}\text { Eruta } \\
(8)\end{array}$ & $\begin{array}{c}\text { Befinada } \\
\text { (9) }\end{array}$ \\
\hline $\begin{array}{r}109362 \\
135605 \\
90785 \\
66697 \\
76 \quad 680\end{array}$ & $\begin{array}{r}130000 \\
163000 \\
111616 \\
75538 \\
90268\end{array}$ & $\begin{array}{ll}31 & 864 \\
22 & 698 \\
26 & 606 \\
30 & 122 \\
38 & 441\end{array}$ & $\begin{array}{c}20.0 \\
5-6 \\
5-6 \\
7-10 \\
7-10\end{array}$ & $\begin{array}{r}32 \\
3 \\
0 \\
0 \\
0\end{array}$ & $\begin{array}{r}5620 \\
2071 \\
946 \\
441 \\
456\end{array}$ & $\begin{array}{lr} & 84 \\
37 & 026 \\
41 & 734 \\
20 & 820 \\
26 & 701\end{array}$ & $\begin{array}{c}24.1 \\
20.7 \\
= \\
18.0\end{array}$ & $\begin{array}{l}31.0 \\
26.6 \\
26.2 \\
23.1 \\
22.9\end{array}$ \\
\hline $\begin{array}{l}100267 \\
139027 \\
104224 \\
123950 \\
111041\end{array}$ & 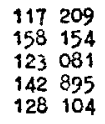 & $\begin{array}{ll}22 & 651 \\
25 & 679 \\
25 & 630 \\
28 & 363 \\
25 & 482\end{array}$ & $\begin{array}{l}7-10 \\
7-10 \\
5-7 \\
5-7 \\
5-7\end{array}$ & $\begin{array}{l}0 \\
0 \\
0 \\
0 \\
1\end{array}$ & $\begin{array}{l}459 \\
280 \\
155 \\
131 \\
145\end{array}$ & $\begin{array}{ll}15 & 270 \\
49 & 413 \\
41 & 694 \\
30 & 340 \\
16 & 311\end{array}$ & $\begin{array}{l}17.1 \\
- \\
17.5 \\
17.5 \\
17.5\end{array}$ & $\begin{array}{l}21.9 \\
22.2 \\
22.8 \\
22.6 \\
20.8\end{array}$ \\
\hline $\begin{array}{r}117852 \\
102668 \\
91488 \\
136485 \\
104386\end{array}$ & $\begin{array}{l}135605 \\
116636 \\
109445 \\
160597 \\
124040\end{array}$ & $\begin{array}{l}39826 \\
51771 \\
58251 \\
59973 \\
84545\end{array}$ & $\begin{array}{l}5-7 \\
7-12 \\
7-12 \\
7-12 \\
7-12\end{array}$ & $\begin{array}{r}2 \\
\quad 657 \\
31946 \\
16822 \\
13766\end{array}$ & $\begin{array}{r}147 \\
1280 \\
11576 \\
24667 \\
5994\end{array}$ & $\begin{array}{rr}2199 \\
106 \\
\\
& 64 \\
& 18 \\
& 40\end{array}$ & $\begin{array}{l}17.5 \\
17.5 \\
15.1 \\
13.9 \\
13.9\end{array}$ & $\begin{array}{l}20.8 \\
20.8 \\
20.8 \\
20.8 \\
20.8\end{array}$ \\
\hline $\begin{array}{ll}115 & 836 \\
147 & 954 \\
121 & 343 \\
229 & 120 \\
274 & 516\end{array}$ & 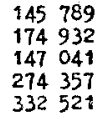 & $\begin{array}{ll}67 & 064 \\
67 & 626 \\
79 & 861 \\
81 & 455 \\
65 & 493\end{array}$ & $\begin{array}{l}7-12 \\
11.0 \\
12.0 \\
12.0 \\
10.0\end{array}$ & $\begin{array}{ll}34 & 088 \\
18 & 156 \\
19 & 033 \\
25 & 489 \\
& 157\end{array}$ & $\begin{array}{ll}22 & 735 \\
33 & 746 \\
11 & 043 \\
49 & 892 \\
6 & 353\end{array}$ & $\begin{array}{r}56 \\
68 \\
6 \\
103 \\
60 \\
64 \quad 690\end{array}$ & $\begin{array}{l}10.5 \\
10.5 \\
11.6 \\
12.0 \\
14.6\end{array}$ & $\begin{array}{l}15.8 \\
17.3 \\
18.6 \\
17.0 \\
19.8\end{array}$ \\
\hline $\begin{array}{r}104045 \\
44586 \\
44465 \\
86878\end{array}$ & $\begin{array}{rr}147 & 959 \\
84 & 244 \\
87 & 362 \\
126 & 664\end{array}$ & $\begin{array}{ll}48 & 046 \\
34 & 080 \\
30 & 535 \\
33 & 707\end{array}$ & $\begin{array}{r}9.0 \\
14.0 \\
17.0 \\
12.0\end{array}$ & $\begin{array}{rr}15 & 1 \\
15263 \\
11 & 339 \\
1 & 852\end{array}$ & $\begin{array}{rr} & 22 \\
15 & 064 \\
148 & 627 \\
31 & 417\end{array}$ & $\begin{array}{r}53823 \\
404 \\
3 z \\
10\end{array}$ & $\begin{array}{c}14.6 \\
14.1 \\
=\end{array}$ & $\begin{array}{c}19.4 \\
18.6 \\
= \\
=\end{array}$ \\
\hline
\end{tabular}

, 1924, p. 281.

(para 1880-1885); E. J. Scheleh, "Los precios de la caña. Su desarrollo his14 (para 1887-1918).

os Aires, Compañía Sudamericana de Billetes de Banco, 1905, pp. 186-187

vesarrollo, 1875-1914, Buenos Aires, Eudeba, 1971 (para 1870); Anuario de , Compañía Sudamericana de Billetes de Banco, 1897, t. II, p. 57 (para 1877$398,1899,1900,1902,1912,1913,1914,1915,1916,1917$ y 1918; Departamento (para 1902-1911).

tavos. d Tasa (porcientos).

A principios del decenio de 1870 encontramos jornales de peones agrícolas muy semejantes en Tucumán, Santiago del Estero y Catamarca, todos entre los ocho y diez pesos bolivianos mensuales (o sea, aproxi-

sentado al Exmo. Sr. Ministro del Interior, Dr. Joaquín V. González, Buenos Aires, 1904; y Boletín de la Dirección General del Trabajo, Núm. 12, 1910. Catamarca; Federico Espeche, La Provincia de Catamarca, Buenos Aires, 1875; Federico Schickendantz et al., Memoria descriptiva de la Provincia de Catamarca, 1881, manuscrito; I. Bialet Massé, op. cit., Santiago del Estero, Alejandro Gancedo, Memoria descriptiva de la Provincia de Santiago del Estero, Buenos Aires, 1885; Antonio 
madamente entre seis y ocho pesos moneda nacional), muy inferiores a los que se acostumbraba pagar en la provincia de Buenos Aires (12.50 pesos moneda nacional).$^{28}$ Ya los datos existentes para los primeros años del decenio de 1880 indican una creciente separación de los jornales tucumanos y los santiagueños y catamarqueños. Mientras que los últimos no se habían modificado, en Tucumán habían subido a 12 pesos bolivianos y se indicaba que en época de zafra no era extraño para un peón hábil ganar 20 pesos bolivianos mensuales. Esta última cifra equivaldría al jornal normal del peón de campo en Buenos Aires, que era de alrededor de 13.50 pesos fuertes. En todas las provincias los jornales rurales incluían, además del pago monetario mencionado, la alimentación y a menudo la vivienda, aunque el peso económico de esta última fuese bajo y rara vez era estimado como un costo en la época. La comida sí lo era y significaba una parte importante del jornal, sobre todo cuando éste era bajo. ${ }^{2 \theta}$ En las áreas de salarios más deprimidos la comida agregaba quizás un $50 \%$ al jornal del peón.

Hacia 1895 las diferencias entre Catamarca y Santiago, por una parte, y Tucumán, por la otra, eran notorias. En ese año se produjo el pico del empleo en Tucumán, debido a la fuerte expansión del área cultivada

Correa y Emilio Lahitte, Investigación parlamentaria sobre agricultura, ganaderia, industrias derivadas y colonización, Anexo G, Buenos Aires, Cámara de Diputados de la Nación, 1898; Bialet Massé, op. cit., Buenos Aires, Investigación parlamentaria, op. cit., Anexo, Buenos Aires; William I. Buchanan, La moneda y la vida en la República Argentina, en Revista de Derecho, Historia y Letras, tomo II, Buenos Aires, 1898; Bialet Massé, op. cit.; Estadisticas Agrícolas, 1915-1916; Boletín de la Dirección General del Trabajo, Núm. 21 (estos dos últimos reproducidos en Roberto Cortés Conde), El mercado de trabajo, Instituto Torcuato Di Tella, mimeografiado.

28 La complicada evolución del sistema monetario argentino y las equivalencias de distintas monedas son descritas por Juan Alvarez, Temas de historia económica-argentina, Buenos Aires, El Ateneo, 1929. La conversión de pesos bolivianos en pesos fuertes, o luego pesos moneda nacional, la hemos hecho siguiendo referencias de la literatura de la época (en ocasiones la misma que ofrece datos sobre salarios y precios), y no la conversión oficial citada por Alvarez. Este nos relata que la ley de 1876 estableció una conversión del peso boliviano en 0.72 pesos fuertes, pero en el Boletin del Departamento de Agricultura, o en Gancedo, encontramos que la tasa de conversión era de 0.56 , que adoptamos como más aproximada a la realidad.

29 La descripción que nos ofrecen diversos autores sobre este aspecto es bastante detallada, Gancedo afirma que en Santiago "la comida que se les da (a peones trabajadores) además del sueldo mensual o diario que ganan, son dos «locros» y una «mazamorra». En cada locro se calcula 11/2 libras de maíz, una de carne (tumba) para un peón; y en la mazamorra dos libras" (Gancedo, op. cit., p. 123). La comida o ración subsistía como forma de pago en la agricultura cañera a principio de siglo. Bialet Massé la describe así: "la ración consiste en 1300 gramos de carne, la que vi aquel día era excelente; 1300 gramos de maíz y tres galletas, que pesan 840 gramos... se les da la sal, café y azúcar, y en las noches frías caña, en la proporción de tres litros para cada 30 hombres..." (Bialet Massé, op. cit., p. 523). 
y a los altos precios de la caña prevalecientes (véase el cuadro 2). Las cifras disponibles indican salarios rurales semejantes en Tucumán y Buenos Aires, donde todavía la crisis de 1890 había dejado rastros importantes. Pero aún hacia principios de siglo, cuando el ciclo ascendente volvió a caracterizar la economía pampeana, las diferencias seguían siendo pequeñas. Por supuesto, siempre se consideran los jornales de peones rurales sin tomar en cuenta dos elementos cruciales para determinar el ingreso del sector trabajo: la estacionalidad del empleo y las diferencias internas entre trabajadores. Pero aún así resulta algo sorprendente la paridad de salarios que encontramos a fines del siglo pasado y comienzos del presente.

Por supuesto, los salarios monetarios así expresados deben interpretarse con suma cautela, por lo menos hasta saber qué se podía comprar con el mismo dinero en distintas provincias y, quizás más importante, cuánto del salario nominal era efectivamente percibido. Con respecto al primer problema, diversos autores coinciden en informarnos del alto costo de la vida en Tucumán hacia 1895. Para ese año tenemos también datos bastante completos sobre precios de artículos alimenticios que indicarían que, en caso de haber alguna diferencia con Buenos Aires, ésta sería en la dirección de un costo más alto en la provincia del norte. Algunos datos, limitados a 1895, son indicativos: al menos la carne y el trigo, elementos básicos de la dieta argentina (aunque en el norte el maíz reemplazase en las clases bajas la importancia del trigo, más "europeo"), eran más baratos esos años en Buenos Aires que en Tucumán. ${ }^{30}$ Esto no debiera sorprendernos dada la especialización de la pampa húmeda en esos productos. Además, puede muy bien suponerse que otros artículos, en especial los importados, resultarían bastantẹ más caros en Tucumán

30 En 1895 los precios corrientes en Tucumán y la capital Federal para diversos artículos eran los siguientes:

Pan (kilo)
Carne vacuna (kilo)
Azúcar 1: (kilo)
Vino del país, común (litro)
Maíz en grano (kilo)
Café (kilo)
Harina de trigo (kilo)
Harina de maíz (kilo)
Arroz del país, 2a (kilo)
Yerba (kilo)
Carbón (bolsa)

$\begin{array}{cc}\text { Tucumán } & \text { Capital Federal } \\ \$ 0.30 & \$ 0.25 \\ \$ 0.30 & \$ 0.25 \\ \$ 0.40 & \$ 0.42 \\ \$ 0.50 & \$ 0.40 \\ \$ 0.10 & -\overline{-} \\ \$ 2.00 & \$ 1.90 \\ \$ 0.10 & \$ 0.17 \\ \$ 0.25 & - \\ \$ 0.30 & \$ 0.35 \\ \$ 0.90 & - \\ \$ 0.80 & -\end{array}$

Los datos tucumanos son del Anuario de Estadistica de la Provincia de Tucumán, 1895, Buenos Aires, Compañía Sud-Americana de Billetes de Banco, 1896, tomo II, pp. 610-611. Los porteños son de W. I. Buchanan, La moneda y la vida en la República Argentina, tomo II, Buenos Aires, 1898. 
que en el litoral, por la diferencia obvia de fletes o, en el caso de aún persistir la producción local, por lo más barato del producto industrial importado.

El segundo aspecto mencionado, la proporción del salario realmente percibida, es más difícil de valorar. Es conocido que, mediante el sistema de adelantos y por el pago en vales canjeables en negocios del mismo ingenio por bienes de consumo, ambos comunes en la época en todo el país pero mucho más arraigados en Tucumán, el ingenio obtenía una ganancia extra, o lo que es lo mismo, disminuía su costo de mano de obra. Sin embargo, nos inclinamos a pensar que el peso de estos factores en disminuir el salario real de los trabajadores no fue decisivo, e incluso que la obtención de un excedente mayor no fuese el principal motivo de su existencia. De hecho, aunque sea difícil demostrarlo, parece que el pago en vales reflejase más que nada una tremenda escasez de circulante (es decir, tomaba la forma de creación de medios de pago, como muchos otros en la época), mientras que el sistema de adelantos resultaba costoso para el ingenio pero imprescindible como medio de reclutamiehto de una mano de obra con medios alternativos de vida. Este aspecto del sistema de explotación de la fuerza de trabajo es sin duda esencial y conviene discutirlo a continuación con más detalle dentro de una descripción global de las formas de reclutamiento y disciplina de los trabajadores, descripción que permitirá ligar dichos sistemas con el origen social del proletariado azucarero.

\section{Métodos coercitivos}

La legislación represiva de la vagancia, de origen colonial, se expandió por todo el país durante el siglo XIX como medio restrictivo del bandidaje pero sin duda también como sistema de reclutamiento forzoso de trabajadores para el campo y soldados para las milicias, sobre todo en la frontera con el indio. ${ }^{31}$ La bajísima densidad demográfica estaba en la base de ambos objetivos; por una parte, daba lugar a modos libres de vida que lindaban a menudo en el bandidaje, el robo de ganado, etc. Por la otra al permitir dichos modos, hacía poco atractivo al trabajo asalariado, aun con salarios altos. En el litoral, la expansión territorial de las estan-

31 Gastón Gori describe en detalle las provisiones de diversas leyes provinciales del siglo XIx, en buena medida heredadas de las leyes de Indias: “...nuestra legislación sobre vagos y mal entretenidos no le va muy en zaga a la española de la conquista y la colonia, ni por escasa en su número ni por benévola en sus sanciones". Gori, sin embargo, enfatiza el papel de dicha legislación en excluir a la población que molestaba a la estancia del litoral: "La estancia dotada ya de peones y mayordomos, repulsaba a las familias menesterosas, no daba lugar a que se afincaran los hombres pues estaba consagrada al ganado. Quienes no trabajaban en ellas pero sin embargo hallaban allí su alimento o su refugio, eran holgazanes o cuatreros". Gastón Gori, Vagos y malentretenidos: Aporte al tema Hernandiano, Santa Fe, Colmegna, segunda edición, 1965, citas en páginas 14 y 31. 
cias y su demarcación, aunque provisoria y endeble, pretendía junto con la legislación represiva "cercar" a la mano de obra tanto como al ganado. 32

En el norte, más denso y estable, con el peligro indígena más alejado y la propiedad más demarcada, tampoco dejaba de tener importancia tal legislación represiva. Las guerras y la ruptura de líneas comerciales habían aumentado la inseguridad general y grandes áreas eran, aunque más libres de ataques indígenas, igualmente desérticas y comparables en este sentido al litoral o al noreste. En Tucumán, como en otras provincias, los reglamentos de policía contenían secciones dedicadas, de manera conjunta, a la represión de la vagancia y al trabajo de jornaleros y domésticos. Aunque la Constitución de 1853 garantizaba la libertad de trabajo (y la de no trabajo) dichos códigos inconstitucionales sobrevivieron varios decenios.

El reglamento de policía de 1856 contenía un capítulo sobre el servicio jornalero que autorizaba a la fuerza a "perseguir a vagabundos y holgazanes de ambos sexos", obligándolos a tomar ocupación lícita, registrando a peones y sirvientes y acreditándolos como tales mediante papeletas en que constase su servicio con un patrón. ${ }^{33}$ También regulaba la forma de trabajo ("de sol a sol"), las obligaciones del patrón (el pago del salario y dos comidas diarias), y la autoridad de éste sobre aquél, incluido su revestimiento de autoridad policial para guardar el orden y corregir la conducta de sus peones. En el año 1877 dicho reglamento fue reforzado y actualizado, proveyendo castigos más severos para el ocultamiento de peones o la contratación de aquellos que no hubiesen sido liberados de su contrato por patrones anteriores. Intentaba impedir, de esta forma, el robo de peones (con el consiguiente perjuicio para aquel que hubiese adelantado jornales, como era común), pero también limitar la competencia con su efecto ruinoso sobre los salarios. Algunos artículos en defensa de los peones son, por lógica, demostrativos de prácticas comunes que se intentaba frenar. Así, el artículo 71 indicaba una multa para el patrón que le fuese probado fraude en los ajustes del pago a sus peones. También prohibía adelantar salarios por más de la mitad del término convenido, cuando hubiese un plazo determinado, y en caso de no haberlo el adelanto no podría exceder dos meses de salario. Estas medidas, junto con la extensión máxima del contrato por un año, intentaban

32 Tulio Halperín Donghi, "La expansión ganadera en la campiña bonaerense (1810-1852)", Desarrollo Económico, 3, abril-septiembre de 1963.

${ }^{33}$ Los textos de los reglamentos de policía y la Ley de Conchabos han sido consultados en la versión que aparece en La legislación laboral en Tucumán, op. cit. En el mismo tomo puede encontrarse el decreto provincial que reguló la contratación del trabajo entre patrones e indios, firmado el 9 de diciembre de 1878 y preparado para acoger los indios que Roca, ministro de Guerra, enviaría del sur, "... sustituyendo estos indios holgazanes y estúpidos (los "matacos" del Chaco) con los Pampas y Ranqueles, que si bien están debajo del nivel moral y civilización relativa del gaucho, no les ceden en inteligencia y fortaleza". La cita es de una carta de Roca al gobernador de Tucumán del 4 de noviembre de 1878 . 
impedir el endeudamiento que fijase al peón al servicio de un patrón determinado.

Pero también el nuevo reglamento de policía evidencia con claridad lo que ya se atisbaba en el anterior: el principal empleador de jornaleros era el plantador de caña de azúcar y su mayor necesidad era estacional, en la época de la zafra, cuando necesitaba sustraer de otras ocupaciones toda la mano de obra disponible. De allí, quizás, la defensa que el reglamento de policía hacía contra el endeudamiento prolongado y el contrato de trabajo de largo plazo. También, como en 1856, el reglamento establecía una jornada de trabajo más prolongada en la época de la zafra.

En el año 1882, según datos del Registro Estadístico de la Provincia, se "conchabaron" 14780 peones y 1559 sirvientes, la mayoría de los primeros para el trabajo rural y de los segundos en el trabajo doméstico. Una idea de la evolución del empleo de jornaleros rurales en esos años, que como vimos fueron de fuerte expansión del área cultivada con caña de azúcar, puede tenerse por vía indirecta. Los patrones debían pagar, por cada papeleta de "conchabo" de peones, la suma de dos reales; esta suma, junto con otras de orígenes diversos, constituía el ingreso contabilizado como "eventuales de policía", que osciló así entre 1877 y 1882: 3 313; 3 378; 6233 ; 6912 y 8885 (en pesos moneda nacional o su equivalente entre 1877 y 1880 , o sea pesos fuertes) ${ }^{34}$ Esto permitiría establecer que, a grosso modo, si el empleo de jornaleros en 1882 era 100, en 1877 había sido 37; como en 1882 había 6636 hectáreas cultivadas con caña y en 18772487 hectáreas, la proporción sería idéntica, 100:37 (véase cuadro 1). Aunque no sabemos cuántos de los jornaleros eran contratados para el cultivo de caña, es muy significativo que el empleo global de jornaleros haya crecido en la misma proporción que la superficie cultivada, ya que aquél resultaba evidentemente dominado por el empleo en la caña de azúcar.

A pesar de sus provisiones estrictas, el reglamento de policía no fue suficiente y durante el decenio de 1880 se propuso una ley especial, 1lamada Ley de Conchabos. Dicha ley, propuesta en 1881, fue sancionada en 1888, después de prolongados debates. Por detrás de éstos, parece surgir una distinción entre los grandes ingenios, que por su intermedio esperaban obtener la cantidad de trabajadores que, en años de precios bajos, hacían una diferencia decisiva, y los cañeros medios, quienes no podían esperar sino una competencia desleal de los grandes ingenios; además, otros sectores, en especial políticos liberales, se oponían a la legislación por su carácter claramente represivo, pero al igual que en otras áreas de la política provincial resultaban estar más cerca de los cañeros medios y otros sectores económicos que del sector más concentrado y capitalizado de la industria azucarera. Al poco tiempo de ser 1882.

34 Registro Estadístico de la Provincia de Tucumán correspondiente al año 
sancionada comenzaron los ataques contra la ley, incluido un proyecto emanado del ejecutivo provincial en 1891 para derogarla. Sin embargo, sólo fue derogada en 1896 y de hecho sus efectos se prolongaron varios años, mediante la renovación de contratos firmados cuando aquélla regía. ${ }^{35}$

Formalmente, la Ley de Conchabos sólo completó e hizo más específica la reglamentación del trabajo de jornaleros que ya existía en los códigos policiales. La única novedad de importancia fue la de proveer mecanismos específicos para la persecución de peones prófugos: los peones pasaron a tener libretas, en las que se anotaban entre otras cosas el monto de la deuda contraída y el patrón acreedor. A diferencia de la papeleta, no permitía el cambio de patrón sin antes conseguir la liberación de la deuda y del contrato en la libreta. El número de peones que se fugaban debió entonces ser alto y en crecimiento. Por ello la ley de 1888 estableció una papeleta especial para reclamar a peones prófugos, que firmada por el patrón ponían en funcionamiento un mecanismo policial para dar con el delincuente y obtener el pago de la deuda contraída.

Es indicativo del volumen de mano de obra involucrado el que, en el primer año de funcionamiento del registro que matriculaba a los peones según la Ley de Conchabos 1888-1889, éste incluía 43814 trabajadores (compárese con la población total de la provincia en fechas aproximadas,

\section{Cuadro 3}

Población total, extranjera, Nativa de la provincia y Nativa DE OTRAS PROVINCIAS, 1869-1914

\begin{tabular}{|c|c|c|c|c|}
\hline & & 1869 & 1895 & 1914 \\
\hline Argentine & $\begin{array}{l}\text { Total } \\
\text { extranjeros ( })\end{array}$ & $\begin{array}{c}1743352 \\
21.1\end{array}$ & $\begin{array}{c}3954911 \\
25.4\end{array}$ & $\begin{array}{c}7885237 \\
29.9\end{array}$ \\
\hline Tuoumen & $\begin{array}{l}\text { Total } \\
\text { extrasjeros (x) } \\
\text { nocidos on otras } \\
\text { provinetas ( }(\mathrm{x})\end{array}$ & $\begin{array}{c}108953 \\
0.3 \\
8.9\end{array}$ & $\begin{array}{c}215742 \\
4.9 \\
19.0\end{array}$ & $\begin{array}{c}332033 \\
9.8 \\
16.7\end{array}$ \\
\hline $\begin{array}{l}\text { Santiago dol } \\
\text { Estoro }\end{array}$ & $\begin{array}{l}\text { Total } \\
\text { oxtranjeros (\&) } \\
\text { nacidos on otras } \\
\text { provincias (f) }\end{array}$ & $\begin{array}{c}132898 \\
0.1 \\
1.4\end{array}$ & $\begin{array}{c}161502 \\
1.4 \\
4.3\end{array}$ & $\begin{array}{c}261678 \\
3.6 \\
6.0\end{array}$ \\
\hline Catanaron & $\begin{array}{l}\text { Total } \\
\text { oxtranjeros (\$) } \\
\text { naoidos on otras } \\
\text { provinoias (\$) }\end{array}$ & $\begin{array}{l}79.962 \\
0.5 \\
6.1\end{array}$ & $\begin{array}{l}90161 \\
1.2\end{array}$ & $\begin{array}{c}100391 \\
2.3\end{array}$ \\
\hline
\end{tabular}

Fuente: Censos nacionales, 1869, 1895, 1914.

35 Véase respecto de la discusión política alrededor de la Ley de Conchabos: Guy, op. cit., pp. 249-250, y Manuel García Soriano, "La condición social del trabajador en Tucumán durante el siglo xIx", Revisión histórica, vol. I, Núm. 1, Tucumán, mayo de 1960; y "El trabajo en los ingenios azucareros de Tucumán", Revista de la Junta de Estudios Históricos de Tucumán, vol. II, Núm. 2, julio de 1969. 
en el cuadro 3) ${ }^{36}$ En el año 1895 las estadísticas indican un total de 34181 conchabos efectuados, casi la mitad de los cuales se concentraron en los meses de julio, agosto y septiembre. Además, durante dicho año se registraron 2857 papeletas por peones prófugos, más de 1700 de ellas entre julio y agosto.

Es preciso recordar aquí el violento crecimiento del área cultivada y los salarios relativamente altos predominantes alrededor de 1895, para concluir que la legislación represiva tenía como objetivo fundamental mantener un flujo cuantitativamente grande de trabajadores, sobre todo en los momentos claves, que de manera disciplinada se prestasen para la agobiadora tarea sin retirarse de la misma apenas hubiesen ganado "lo suficiente" para pagar sus deudas y llevarse algo de dinero. Es decir, los salarios altos no alcanzaban para reclutar la mano de obra necesaria y aumentarlos ponía en riesgo la ganancia sin seguridad de que creciera la oferta de trabajo. Como se observa en numerosas ocasiones, con una fuerza de trabajo de proletarización reciente, un salario mayor daría lugar a una disminución efectiva de trabajo of recido en el mercado, fenómeno que los economistas conceptualizan como una curva perversa de oferta de trabajo y que ya Weber señalaba como característica de la orientación tradicional de muchos trabajadores. ${ }^{37}$.

Puesto así el problema, se hace necesario revisar considerablemente la perspectiva usual en el área que enfatiza la relación existente entre sistemas coercitivos de obtención de mano de obra y la escasez (y alto precio) de la misma. ${ }^{38}$ En Tucumán podría afirmarse que, aunque en principio encontramos juntas estas variables, la coerción resultó un ingrediente necesario para obtener, aun a salarios relativamente altos, un flujo grande de trabajadores en los momentos necesarios, y aún más importante para conservarlos en los momentos claves. Aun cuando hubiese sido factible un aumento del salario real (o un aumento real mayor, ya que entre 1880 y 1895 probablemente los salarios reales crecieron), no habría crecido significativamente la oferta de trabajo, ni ésta hubiese respondido a la disciplina requerida por los ingenios.

36 P. Rodríguez Marquina, La Provincia de Tucumán: Breves apuntes. Tucumán, El Orden, 1890, p. 15.

37 Una revisión del comportamiento de curvas de oferta de trabajo puede encontrarse en Richard Perlman, Labor Theory, Nueva York, John Wiley \& Sons, 1969, en especial pp. 4-13. Max Weber discutió el problema, entre otros lugares, en su Etica protestante y el espiritu del capitalismo, con especial referencia al tradicionalismo de mujeres y trabajadores agrícolas en su comportamiento en el mercado de trabajo.

38 Robert Evans, "Some Notes on Coerced Labor", Journal of Economic History, vol. 30, Núm. 4, diciembre de 1970, pp. 861-866, y E. D. Domar, "The Causes of Slavery or Serfdom", loc. cit., pp. 18-32. 


\section{Redes tradicionales}

A los salarios altos y mecanismos coercitivos para reclutar y retener mano de obra, se agregó el uso de redes sociales tradicionales y otras que, aunque nuevas, se asemejaban mucho a aquéllas. Nos referimos a vínculos personales de lealtad y confianza típicos de comunidades rurales que fueron, desde temprano en el desarrollo de la agricultura de la caña de azúcar, utilizados para contratar jornaleros provenientes de regiones más o menos distantes. La persona clave que surgió con la actividad nueva fue el contratista, que recibía una comisión por cada trabajador que conchababa para el ingenio (en este y otros aspectos de la descripción uno se siente tentado a utilizar el tiempo presente; los contratistas aún dominan el reclutamiento de jornaleros para la zafra norteña, aunque no la tucumana en igual medida. Su papel, sin embargo, ha cambiado de manera radical desde que la economia azucarera ha trabajado con excedentes de mano de obra más o menos constantes. Si antes su existencia era crucial para el ingenio, ahora el contratista sirve a éste como filtro, casi como una oficina de selección de personal de corte arcaico, pero para los trabajadores temporarios se ha vuelto esencial medio de conseguir año a año el trabajo, odiado pero codiciado, en la zafra) ${ }^{39}$ En algunos casos, sobre todo en las comunidades agrícolas catamarqueñas, hacendados, comerciantes y jefes políticos locales comenzaron a hacer las veces de contratistas, facilitando el reclutamiento de sus propios peones u otros que conocían y sobre los cuales tenían influencia, y ganando una cantidad extra en el transporte de los mismos. En otros casos, quizás la mayoría, el contratista negociaba con jefes locales, incluidos los caciques indígenas, el "alquiler" de población bajo el dominio tradicional de éstos, repartiendo la comisión. Aunque nuestro conocimiento de estos sistemas es precario, dada la ausencia de descripciones contemporáneas al período inicial, parece significativo subrayar que ellos incluían a grupos dominantes locales fuera de la región cañera, sobre todo en provincias vecinas, para el reclutamiento de la fuerza de trabajo hacia aquélla.

39 Juan Bialet Massé, El estado de las clases obreras argentinas a comienzos del siglo, reimpresión, Córdoba, Universidad Nacional de Córdoba, 1968, en el capítulo $\mathrm{xx}$, sobre "Agencias de Conchavo", discute cómo operaban a príncipios de siglo, en especial en el Litoral. Bajo sistemas más coercitivos y con menor control legal, operaban los contratistas en áreas del interior. Dos casos son particularmente conocidos por el uso de la violencia en manos particulares o en complicidad con la autoridad pública: el reclutamiento de indios chaqueños para la zafra azucarera norteña y el trabajo de los mensús en los yerbatales de Misiones y el Paraguay. Ambos casos fueron vívidamente descritos por un funcionario del Departamento de Trabajo, José Elías Niklison; ver Boletín del Departamento Nacional del Trabajo, Núm. 26, abril 30 de 1914, en especial pp. 53-59, y Núm. 28, agosto 31 de 1914, pp. 21-29. En cuanto a su continuación en nuestros días con funciones cambiadas, véase Scott Whiteford, "Social Articulation and Power: the Zafrero and the Plantation Environment", trabajo presentado a la Conferencia sobre Procesos de Articulación Social, Buenos Aires, 1974, mimeografiado. 
Los ingenios también tenían, y tienen, otras propiedades fuera de la región cañera. Además de permitir cierta diversificación, el motivo principal para su existencia fue el que permitían completar el ciclo anual del empleo de la mano de obra y así asegurarla para la parte esencial del mismo, es decir, la estación de la zafra. Bialet Massé indicaba a principios de siglo que cierto ingenio conservaba extensiones de tierras en Santiago del Estero "... que dan trabajo al obrero o se le dan animales o terrenos en arrendamiento, con la condición de que vaya a trabajar al ingenio en la cosecha". ${ }^{40}$ Siete decenios después, Santiago Bilbao observó la operación de sistemas semejantes dentro de la misma provincia de Tucumán, en la que grandes cañeros e ingenios poseen tierras aptas para la ganadería pobre de la sierra cuyo uso es, en gran medida, orientado a sostener y retener mano de obra necesaria para la zafra. ${ }^{41}$ Todo hace pensar, aunque no tengamos evidencias, que ya hacia 1880 y sobre todo cuando la economía azucarera santiagueña entró en crisis después de 1890 , tales sistemas de propiedad orientados al dominio sobre la fuerza de trabajo ya existian.

Una vez en el ingenio, la formación de grupos de trabajo se hacía sobre la base del origen de contratación, a menudo incluyendo trabajadores vinculados por el parentesco. Este sistema permitía totalizar ingresos considerables a los trabajadores a destajo, que en grupos familiares podían contar con la ayuda de mujeres y niños. La migración de grupos familiares era más común entre santiagueños que catamarqueños, por diversas razones. Una de ellas era la mayor distancia y riesgo al descender de los altos valles de la llanura subtropical tucumana. Otra, la ocupación femenina predominante en las comunidades catamarqueñas, en la artesanía textil, que hacía menos deseable su movilización hacia la zafra. La principal evidencia de esta característica diferencial es la mayor masculinidad de la migración catamarqueña en comparación con la santiagueña, registrada por los censos. ${ }^{42}$ De cualquier manera, la conformación de grupos de trabajo homogéneos en su origen geográfico era también relevante para facilitar el control de los trabajadores, quienes aislados de otros ingenios y de centros urbanos, tenían relaciones personales con el contratista y con compañeros de trabajo que los ataban tanto como las condiciones del conchabo, pero haciendo más pasajera la estadía en una situación regimentada durante varios meses.

40 Bialet Massé, op. cit., pp. 529-530.

41 Santiago Bilbao, "Formas productivas de la provincia de Tucumán", documento interno de trabajo del Instituto Nacional de Tecnología Agropecuaria, mimeografiado.

42 Roberto A. Miatello, Migraciones de población de la provincia de Catamarca, Córdoba, Universidad Nacional de Córdoba, 1960, capítulo II. 


\section{Estancamiento en áreas de emigración}

Salarios, legislación represiva, redes de influencia y sistemas de propiedad se conjugaron entonces para hacer posible la solución al problema de la mano de obra generado por la expansión del cultivo de la caña de azúcar. Estos elementos operaron sobre la base, por una parte, de la ampliación de un mercado interno protegido que hacía tal expansión deseable, y por la otra, del prolongado estancamiento y crisis de otros sectores de la economía del noroeste. Sólo podemos entrar en forma superficial en este tema, casi lugar común de la historiografía argentina, pero desconocido en sus detalles y su articulación global. ${ }^{43}$

Los trabajos de Espeche, publicados en 1875, y de Schickendantz y colaboradores, de 1881 , dejan pocas dudas de que la economía catamarqueña continuaba hacia comienzos de la expansión azucarera un estancamiento ya secular. ${ }^{44}$ No podemos entrar aquí en sus causas profundas, pero el diagnóstico era claro: una economía históricamente formada alrededor de vías comerciales, hacia el norte con Salta y Bolivia, a través de los Andes con Chile y hacia el sur con Cuyo, había perdido casi toda posibilidad comercial en escala congruente con su peso demográfico. Ya en 1869 , fecha del primer censo nacional, Catamarca era provincia de emigración. Las descripciones, departamento por departamento, dejan pocas dudas que la actitud comercial quedaba pero los productos que podían colocarse ventajosamente en el mercado eran cada vez menos. El oeste catamarqueño, próximo a Tucumán aunque separado por montañas, había girado hacia esa dirección durante varios decenios, e incluso había sufrido un intento de anexión. ${ }^{45}$ A diferencia del este, la actividad agrícola era importante en los valles irrigados. Cereales, y en forma creciente vinos y aguardiente, eran los principales productos de exportación. Pero el aumento del mercado provocado por la expansión azucarera poco parece haberla beneficiado: el aislamiento siguió siendo grande, con fletes costosos y travesías peligrosas, frente a un ferrocarril que hizo en poco tiempo más baratos al vino, la harina y otros productos importados de

43 Véase por ejemplo, Aldo Ferrer, La economía argentina, Buenos Aires, Fondo de Cultura Económica, 1963.

44 Federico Espeche, La provincia de Catamarca, Buenos Aires, 1875; Federico Schickendantz y Samuel A. Lafone Quevedo, Las industrias de la provincia de Catamarca, Catamarca, Imprenta del Estado, 1881; y Samuel A. Lafone Quevedo y Federico Schickendantz, Memoria descriptiva de la Provincia de Catamarca, 1881 , inédito (Biblioteca Tornquist, Buenos Aires). Quizás la única actividad nueva que genera algún entusiasmo localizado en la segunda mitad del siglo XIX es la minería del cobre.

45 Véase Rodolfo A. Cerviño, "Los departamentos del oeste de la provincia de Catamarca y su anexión provisoria a la provincia de Tucumán", Trabajos y Comunicaciones, La Plata, 1968, pp. 107-118. 
Buenos Aires, aunque no siempre producidos allí. ${ }^{46}$ Incluso entre 1888 y 1895, fechas de dos censos agropecuarios, la superficie sembrada disminuyó en Catamarca; si bien el primer censo es defectuoso, puede afirmarse sin duda que por lo menos no creció. Catamarca recibió los beneficios del ferrocarril muy tarde y muy parcialmente como para introducir su producción artesanal en mercados ya abarrotados por la producción masiva, nacional o importada.

De los departamentos del oeste catamarqueño, y en menor medida del resto de la provincia, la población agrícola masculina comenzó a emigrar en forma estacional o permanente a Tucumán, dejando en el primero de lós casos a las mujeres a cargo de la actividad artesanal por excelencia, los telares. Los meses muertos en la agricultura de los valles irrigados coincidían con los meses de zafra azucarera en Tucumán, lo que facilitaba el traslado estacional.

En Santiago del Estero la situación fue diferente. Allí también el estancamiento persistía de tiempos de la crisis de la producción algodonera colonial, quizás de antes, cuyo eje había sido. Los santiagueños ya levantaban cosechas de cereales en el litoral hacia el primer decenio del siglo xIx. Desde mediados del decenio de 1870 hubo un auge relativo en lä provincia, coincidente con el derrocamiento del prolongado poder de los Taboada y la llegada del ferrocarril. ${ }^{4 \pi}$ Éste, sin embargo, puede decirse que más que llegar rodeó a la provincia. El de Córdoba a Tucumán tomó la ruta que, sobre el límite entre Santiago y Catamarca, más alejada quedaba de la capital santiagueña y de la mesopotamia fértil irrigada por los ríos Dulce y Salado. Igualmente, el ferrocarril de Tucumán a Sunchales, que evitó el traspaso en Córdoba, rodeó por el este a dicha región. Un ramal especial, de Santiago a Frías y de allí a Córdoba, aunque tarde y en forma costosa, solucionó el problema. Pero éste indica el desfavor político y el escaso potencial económico atribuido a la provincia.

Con todo, la caña comenzó a cultivarse cerca de la capital en 1876 a imitación del boom tucumano y con gran apoyo de las nuevas autoridades; éstas exoneraron de impuestos fiscales por diez años a quienes plantasen al menos diez cuadras de caña (poco más de 20 hectáreas), en 1876, y en 1878 un decreto especial liberó de todo impuesto, por 15 años, al mayor productor de la región. Esta medida se repitió dos años después con otro plantador de caña. Aunque mucho más moderado que el proceso tucumano, el de Santiago fue también de optimismo por encontrar un producto exportable más allá de la frontera provincial que no fuese gente. Sin embargo, no fue amplio ni sostenido aquel entusiasmo, ya que se basó en dimensiones necesariamente menores debido a la

46 Schickendantz y Lafone Quevedo, op. cit., p. 50.

47 Alejandro Gancedo, Memoria descriptiva de la Provincia de Santiago del Estero, Buenos Aires, 1885; Hebe M. C. Vessuri, La expansión agrícola de la década del Ochenta: el caso de una región mediterránea, Tucumán, cis, sin fecha, mimeografiado. 
limitación del área irrigada y la desprotección política. Tucumán había tomado la delantera y atraía necesariamente a la población de departamentos vecinos, aquí poco distantes y sin obstáculos naturales de importancia. Como en Catamarca, los empleadores santiagueños contaban, aunque sin mucho entusiasmo, con el efecto del temido "chucho" (fiebre malárica) que azotaba a Tucumán y con la lealtad de los peones para no quedarse sin trabajadores, pero pronto descubrieron que tal cosa no era posible, ni efectivas las protestas del gobierno provincial frente a la acción de los contratistas. ${ }^{48}$

De cualquier forma, en 1890 el desvío del curso del Río Salado dio con tierra cualquier esperanza de expansión de la producción cañera. Fue en esas fechas que el Chaco santiagueño comenzó a abrirse, con los obrajes empujando del Chaco santafesino en búsqueda de quebracho para la producción de tanino, con lo que una nueva área se abrió para dar lugar a la emigración procedente de la región de asentamiento colonial más arraigado. Población indígena del Chaco, expulsada por la expansión de los obrajes, pasó a contar como mano de obra barata e insuficiente. (De allí que Santiago muestre tasas de crecimiento razonablemente altas entre 1869 y 1914 , ya que en la primera fecha la población indígena estaba excluida de la operación censal.) Fue entonces, además, que comenzó a formarse un sistema de migraciones estacionales múltiples que sobrevivió a nuestros días: de la zafra tucumana, al obraje maderero en el Chaco santiagueño, y algo después a la cosecha algodonera del Chaco propiamente dicho. ${ }^{40}$ En las áreas centrales de Santiago quedaba la reducida agricultura de riego y la extendida ganadería de la hacienda norteña. El santiagueño reforzaba y ampliaba su caracterización secular de migrante dentro del territorio argentino, con gran tendencia al retorno pero con saldos negativos amplios y persistentes.

Las estimaciones de saldos migratorios de la población nativa y extranjera, realizadas por Recchini de Lattes y Lattes, permiten afirmar cuantitativamente las impresiones que ofrecen los datos censales. ${ }^{50}$ Al utilizar los cálculos basados en la diferencia entre provincia de nacimiento y provincia de registro, ya que las estimaciones por tasas de sobrevivencia nos merecen poca confianza por la elevada mortalidad de la región en

48 Afirma Gancedo: “. . . la peonada que antes emigraba a buscar trabajo allí y en otras provincias, ahora no tiene necesidad de salir por que lo encuentra aquí mismo; además el miedo al chucho en Tucumán hace que por más sueldo que les ofrezcan no quieran ir, y esto mismo hará que la emigración extranjera venga con preferencia a esta Provincia, aunque no tuviera las ventajas que ofrece Tucumán con el mayor salario", op. cit., p. 127.

49 Bilbao, op. cit.; y "Migraciones estacionales, en especial para la cosecha del algodón, en el norte de Santiago del Estero", Cuadernos del Instituto Nacional de Antropologia, № 7, 1968-1971, pp. 327-365.

50 Zulma L. Recchini de Lattes y Alfredo E. Lattes, Migraciones en la Argentina: Estudio de las migraciones internas $e$ internacionales, basados en datos censales, 1869-1960, Buenos Aires, Editorial del Instituto, 1969. 
comparación con el país, dicho trabajo concluye que Tucumán en el período 1869-1895 fue cuantitativamente la segunda provincia con mayor saldo positivo. Hacia Tucumán se dirigieron cuatro corrientes importantes, de Santiaga y Catamarca en primer lugar y de La Rioja y Córdoba en segundo lugar, con un total de $\mathbf{2 8} 000$ personas (algo menos que Santa $\mathrm{Fe}$, que tuvo el saldo positivo mayor del período). Ya en el período siguiente, entre 1895-1914, Tucumán tuvo un saldo positivo mucho menor con Santiago y Catamarca, con un total de 10000 personas.

Como señalamos antes, hacia principios del 90 Tucumán comenzó a recibir una cantidad importante de inmigrantes europeos, aunque nunca fue una inmigración masiva como en el litoral. El salto entre 1895 y 1914 es de unas 20000 personas, totalizando en esta última fecha más de $10 \%$ de la población total (véase el cuadro 4). Pero la inmigración

Cuadro 4

Tucumán: Población NATIVA Y extranjera, POR SEXo Y LOCALIDAD, 1914

\begin{tabular}{|c|c|c|c|c|c|c|}
\hline & \multicolumn{3}{|c|}{ Bativo } & \multicolumn{3}{|c|}{ Extranjeroo } \\
\hline & Bonbras & Injores & Total & Hombroa & Mujeros & TotaI \\
\hline $\begin{array}{c}\text { Orbano } \\
x\end{array}$ & $\begin{array}{c}58075 \\
19.3\end{array}$ & $\begin{array}{c}63051 \\
21.0\end{array}$ & $\begin{array}{c}121126 \\
40.3^{126}\end{array}$ & $\begin{array}{c}14869 \\
45.6\end{array}$ & $\begin{array}{l}7604 \\
23.3\end{array}$ & $\begin{array}{c}22472 \\
68.9\end{array}$ \\
\hline$\underset{x}{\text { Aural }}$ & $\begin{array}{c}94 \quad 154 \\
31.4\end{array}$ & $\begin{array}{c}85035 \\
28.3\end{array}$ & $\begin{array}{c}1791^{89} \\
59.7\end{array}$ & $\begin{array}{l}7699 \\
23.6\end{array}$ & $\begin{array}{c}2447 \\
7.5\end{array}$ & $\begin{array}{c}10146 \\
31.1\end{array}$ \\
\hline $\operatorname{Total}_{x}$ & $\begin{array}{c}152229 \\
50.7\end{array}$ & $\begin{array}{c}148086 \\
49.3\end{array}$ & $\begin{array}{c}300315 \\
100.0\end{array}$ & $\begin{array}{c}22567 \\
69.2\end{array}$ & $\begin{array}{c}10051 \\
30.8\end{array}$ & $\begin{array}{r}32618 \\
100.0\end{array}$ \\
\hline
\end{tabular}

europea, como sucedió en otras regiones del país, se ubicó desde su inicio en forma diferencial dentro de la fuerza de trabajo. En Tucumán su aporte fue nulo a la agricultura de la caña de azúcar. No así en el trabajo azucarero fabril, donde no sólo el personal técnico y obrero especializado fue casi totalmente inmigrante, sino entre $10 \%$ y $20 \%$ de la fuerza obrera general. Con todo, la mayor concentración se dio en tareas urbanas, comercio y servicios, aunque en muchos casos se ejercieron en áreas rurales y vecindades de los ingenios. El comercio minorista y ambulante, por ejemplo, fue dominado por inmigrantes extranjeros. Una impresión global puede tenerse al observar en el cuadro 4 la distribución de la población nativa y extranjera por sexo y localidad de residencia. La inmigración extranjera fue masivamente masculina y de residencia urbana. Además, apareció cuando la economía azucarera estaba consolidada (exceptuados algunos pocos técnicos y obreros especializados y no fue un factor que contribuyó a solucionar la demanda de mano de obra de la misma). Sin embargo, aquélla generó actividades en las cuales encontraron mejor ubicación inmigrantes que nativos. Indirectamente, además, la inmigración extranjera contribuiría a solucionar el problema de la mano de obra rural en la caña de azúcar al contribuir a saturar el mercado de trabajo urbano. 


\section{III}

En las páginas anteriores hemos descrito con cierto detalle los elementos que constituyeron el sistema de reclutamiento y retención de mano de obra en la economía azucarera tucumana, entendiéndolos como complementarios y no como alternativos y, dentro del contexto, cada uno de ellos como condición necesaria pero no suficiente para asegurar la fuerza de trabajo demandada por el desarrollo de la producción azucarera en Tucumán. Excedentes demográficos relativos en áreas con cierta densidad constituyeron la oportunidad, que sólo cristalizó en la medida que se organizó un sistema de reclutamiento efectivo y viable políticamente (es decir, un sistema que contase con la aceptación pasiva o el apoyosactivo de la estructura de dominación local) y en que la alta rentabilidad del negocio azucarero permitió ofrecer salarios relativamente elevados. La inserción en el sector nuevo, dificultada por características de la mano de obra reclutada y por el sistema de trabajo en la plantación, fue asegurada con medios francamente coercitivos que operaron para retener durante el tiempo necesario a los trabajadores reclutados estacionalmente.

Sin duda, la descripción es mucho más borrosa cuando tocamos el problema de las estructuras que liberaban mano de obra en el proceso. Sabemos poco sobre la situạción de la agricultura tucumana previa a la gran expansión cañera, así como sobre la economía y sociedad en las dos provincias de mayor emigración, Santiago y Catamarca. Aún menor es nuestro conocimiento sobre la organización e inserción económica y política de las poblaciones indígenas del Chaco que tuvieron una participación de alguna importancia en Tucumán y, junto con la mano de obra boliviana, fueron la base principal de la fuerza de trabajo en las plantaciones azucareras del norte, en Jujuy y Salta. Estos temas se investigan actualmente ya que nos parece que la explicación de cómo se organizó la producción en el sector emergente resulta insatisfactoria sin la inclusión de información sobre las estructuras en decadencia. Un aspecto crucial que diferenció al azúcar tucumana de la producción norteña, que no pudimos tratar aquí en detalle, sirve para ejemplificar este problema: mientras que en Tucumán el sector agrícola-cañero estuvo en una medida considerable desvinculado del sector fabril y se caracterizó por el gran peso del minifundio y la pequeña propiedad, en Salta y Jujuy la industria azucarera estuvo más integrada verticalmente y más concentrada económicamente. La diferencia se explica en parte por la existencia en Tucumán de un sector amplio de pequeños propietarios de la tierra, agricul. tores y ganaderos con orientación comercial, quienes se volcaron a la producción cañera y resistieron la proletarización. Una orientación similar hacia la propiedad de la tierra tenían muchos migrantes santiagueños y catamarqueños que, aunque sólo lo conseguían raramente, se inclinaban a obtener un pedazo de tierra propia. Había, en ese sentido, una sociedad campesina, pero con orientación comercial y no de subsistencia, tanto 
en Tucumán como en las regiones de origen de la mano de obra migrante. Nada de eso se daba en la población indígena del Chaco. Además, es posible que el alto costo de la mano de obra y las dificultades para su reclutamiento hayan incidido en que los ingenios aceptasen la desvinculación del sector fabril y el agrícola, al menos de manera parcial, dominando la situación a través de la comercialización de la caña. De esta forma, colonos en tierras de ingenios (arrendatarios importantes ligados a menudo por parentesco) y cultivadores independientes producían, hacia fines de siglo, cerca de un tercio cada uno de la producción cañera total. El poder seguía concentrado en los ingenios, sin duda, pero los mecanismos de dominación eran más complejos y la situación estructural de la mano de obra en el sector agrícola era más heterogénea que lo que ocurriría 'más tarde en la economía azucarera norteña.

Como resultado de este proceso, que sólo pretendemos haber descrito en sus grandes líneas, el proletariado que emergió alrededor de la producción azucarera tucumana tuvo características distintivas dentro del modelo general de la plantación capitalista. Una de ellas fue la consolidación de un proletariado rural heterogéneo, compuesto por una parte de migrantes estacionales vinculados a otras actividades, parcialmente de subsistencia, el resto del año, y por la otra de trabajadores rurales con posibilidades y ambiciones de una independencia aparente con la transformación en minifundistas comerciales. Tanto en un caso como en el otro la variación entre patrones, o la no monopolización de la tierra por los grandes ingenios, favorecía aún más la heterogeneidad de situaciones. Otra fue la doble separación con el sector fabril, donde los elementos criollos (totalmente predominantes en la producción agrícola) encontraban lugar en los estratos bajos, mientras que inmigrantes de origen europeo ocupaban los lugares de un proletariado especializado y privilegiado en los ingenios.

El comportamiento diferencial de estos sectores del nuevo proletariado tucumano, dentro del sistema cerrado de la plantación azucarera y en las condiciones represivas que predominaron hasta bien entrado el siglo $\mathrm{xx}$, será objeto de análisis posteriores, en los que las características de las otras clases deberán estudiarse con más detenimiento. Aquí pretendimos sólo describir las condiciones de su surgimiento y en especial el papel crucial que jugaron los sistemas de reclutamiento y retención en un momento de gran escasez relativa de mano de obra. 